\title{
Acceptability of online exercise-based interventions after breast cancer surgery: systematic review and narrative synthesis
}

\author{
Mariya B. Sotirova ${ }^{1}$ (D) E Eilís M. McCaughan ${ }^{2} \cdot$ Lucia Ramsey $^{1} \cdot$ Carrie Flannagan $^{2} \cdot$ Daniel P. Kerr $^{1} \cdot$ Sean R. O'Connor ${ }^{3}$. \\ Nicole E. Blackburn ${ }^{1} \cdot$ Iseult M. Wilson ${ }^{4}$
}

Received: 5 May 2020 / Accepted: 30 August 2020 / Published online: 15 September 2020

(C) The Author(s) 2020

\begin{abstract}
Purpose eHealth and mHealth approaches are increasingly used to support cancer survivors. This review aimed to examine adherence, acceptability and satisfaction with Internet-based self-management programmes for post-surgical cancer rehabilitation and to identify common components of such interventions.

Methods Nine electronic databases were searched from inception up to February 15, 2020, for relevant quantitative and qualitative studies evaluating Internet-based cancer rehabilitation interventions. Studies were required to include an exercise or physical activity-based self-management intervention and a measure of adherence, acceptability or user satisfaction with the programme. Two independent reviewers performed all data extraction and quality assessment procedures. Data were synthesized using a narrative approach.

Results Six hundred ninety-six potential papers were identified and screened. Eleven met the inclusion criteria. Interventions had wide variations in levels of adherence, but the majority were reported as being acceptable to the users. Increased acceptability and user satisfaction were associated with interventions which were seen as time and cost-efficient, requiring acquisition of minimal or no new skills, which used coherent language, or which provided tailored information. The majority contained behaviour change components such as goal setting.

Conclusions Despite high levels of heterogeneity between studies, Internet-based approaches may be an acceptable method for the delivery of self-management interventions in post-surgical cancer rehabilitation.

Implications for Cancer Survivors There is a need for further studies exploring factors associated with increased user engagement and usage of digital interventions in cancer rehabilitation settings. These findings should be used to help develop interventions prior to testing their effectiveness in adequately powered randomized controlled trials.
\end{abstract}

Keywords Internet $\cdot$ Adherence $\cdot$ Cancer $\cdot$ Exercise $\cdot$ Rehabilitation $\cdot$ Surgery

Mariya B. Sotirova

sotirova-m@ulster.ac.uk

1 Institute of Nursing and Health Research, Ulster University, Jordanstown, Northern Ireland, UK

2 Institute of Nursing and Health Research, Ulster University, Coleraine, Northern Ireland, UK

3 Centre for Public Health, Queen's University Belfast, Belfast, Northern Ireland, UK

4 School of Nursing and Midwifery, Queen's University Belfast, Belfast, Northern Ireland, UK

\section{Introduction}

Despite increasing incidence, cancer survival rates have doubled in the past 40 years [1]. More than $40 \%$ of people undergo surgical interventions as part of their primary cancer treatment [2] and while many people are able to return to prediagnosis occupations and lifestyle [3-5], treatmentassociated side effects are a common occurrence [6]. This includes functional and musculoskeletal issues such as loss of muscular and cardiac fitness, fatigue, impaired motor sensory function and lymphoedema [6]. Cancer multidisciplinary rehabilitation is found by the literature [7-9] to minimize these effects in its capacity as a key element of the care that cancer patients receive, aiming to minimize long-term complications, reducing hospital re-admissions and improving quality of life 
[7-9]. Cancer rehabilitation assists individuals to achieve the best possible physical, psychological, social and vocational outcomes [10]. A multidisciplinary team approach which anticipates the needs of cancer survivors in a timely, coordinated and continuous manner from the time of diagnosis is recommended [10]. Worldwide policy drivers for patient empowerment during cancer treatments emphasize the need for selfmanagement and person-centred interventions to address unmet care needs [11]. Studies suggest that approximately $40 \%$ of patients report at least one unmet need for rehabilitation services in the immediate recovery period and in the longer term [12-14]. A large-scale cross-sectional survey also showed that $63 \%$ of cancer survivors had a need for at least one type of rehabilitative service, with physiotherapy and physical training being the most often required $(43 \%$ and $34 \%$, respectively) [15].The Internet is a powerful medium for providing accessible and low-cost resources to address unmet support needs in cancer survivorship. Although increasing, the number of these resources is relatively small and there is minimal evidence that describes users' experience of accessing them [16, 17]. Engagement with interventions, facilitators and barriers to their use and users' views on their acceptability, therefore, needs further examination [16-18]. Yardley and colleagues [18] suggest there is a clear distinction between effective engagement with an online intervention which leads to desired outcomes and behavioural change, and a minimal level of engagement, which might not necessarily effect change. Further evidence suggests a number of factors are associated with poor user engagement. This includes the provision of standard information instead of more specialist support and personalization of information [19, 20]. Engagement can, however, be limited by barriers such as lack of experience with using online resources and by usability issues [21, 22]. To inform future research in this area, the aim of this review was to comprehensively examine adherence, acceptability and satisfaction with exercise-based online self-management programmes for post-surgical cancer rehabilitation and to identify common components of such interventions.

\section{Methods}

\section{Study design and search strategy}

This systematic review (PROSPERO registration number: CRD42018107411) was conducted using a predefined protocol developed according to the recommendations of the Cochrane Collaboration Handbook [23] and the Preferred Reporting Items for Systematic Reviews and Meta-analysis (PRISMA) guidelines [24]. Nine electronic databases (The Allied and Complementary Medicine Database (AMED), The Cochrane Library, The
Cumulative Index to Nursing and Allied Health Literature (CINAHL), Excerpta Medica Database (EMBASE), Medical Literature Analysis and Retrieval System Online (MEDLINE), Physiotherapy Evidence Database (PEDro), ProQuest Medical Library, Pubmed and Scopus) were searched from inception to February 15, 2020. Figure 1 presents a copy of the search syntax for the Ovid-EMBASE database to facilitate replication of the search. In order to identify unindexed articles in the searched databases, grey literature was searched using Google scholar, as well as manual searches of the reference lists of relevant articles in the field. The search strategy included a list of concepts (Internet, self-management, exercise, cancer, surgery, response to intervention), with an extensive list of associated keywords and MeSH terms (Table 1). The "explode" command, the truncation symbol $(*)$ and Boolean terms (AND, OR) were applied in order to combine the different search concepts. Two independent reviewers (MS and IW) screened identified titles and abstracts before screening full-text copies of potentially relevant articles based on inclusion and exclusion criteria outlined below. Final agreement on study inclusion was agreed by both reviewers with a third reviewer (LR) consulted to resolve any disagreements (see Fig. 2 for PRISMA flow diagram).

\section{Inclusion and exclusion criteria}

To be included, studies were required to meet the following criteria:

1. Quantitative or qualitative study design

- Included adult participants (aged 18 or over) with at least $2 / 3$ of the study sample having received surgical intervention for any type of cancer

- Included an Internet-based, self-management intervention which included any form of exercise or physical activity, e.g., walking cycling, etc.

- Included at least one measure related to adherence, acceptability and/or satisfaction with the intervention

As the majority of the authors were not multilingual and it was beyond resources of the team to involve a translator, it was decided to restrict the studies examined to those published in English.

\section{Definitions}

For the purposes of this article, the following definitions were used in order to avoid ambiguity in terms of defining Internetbased interventions, adherence, acceptability and satisfaction. 


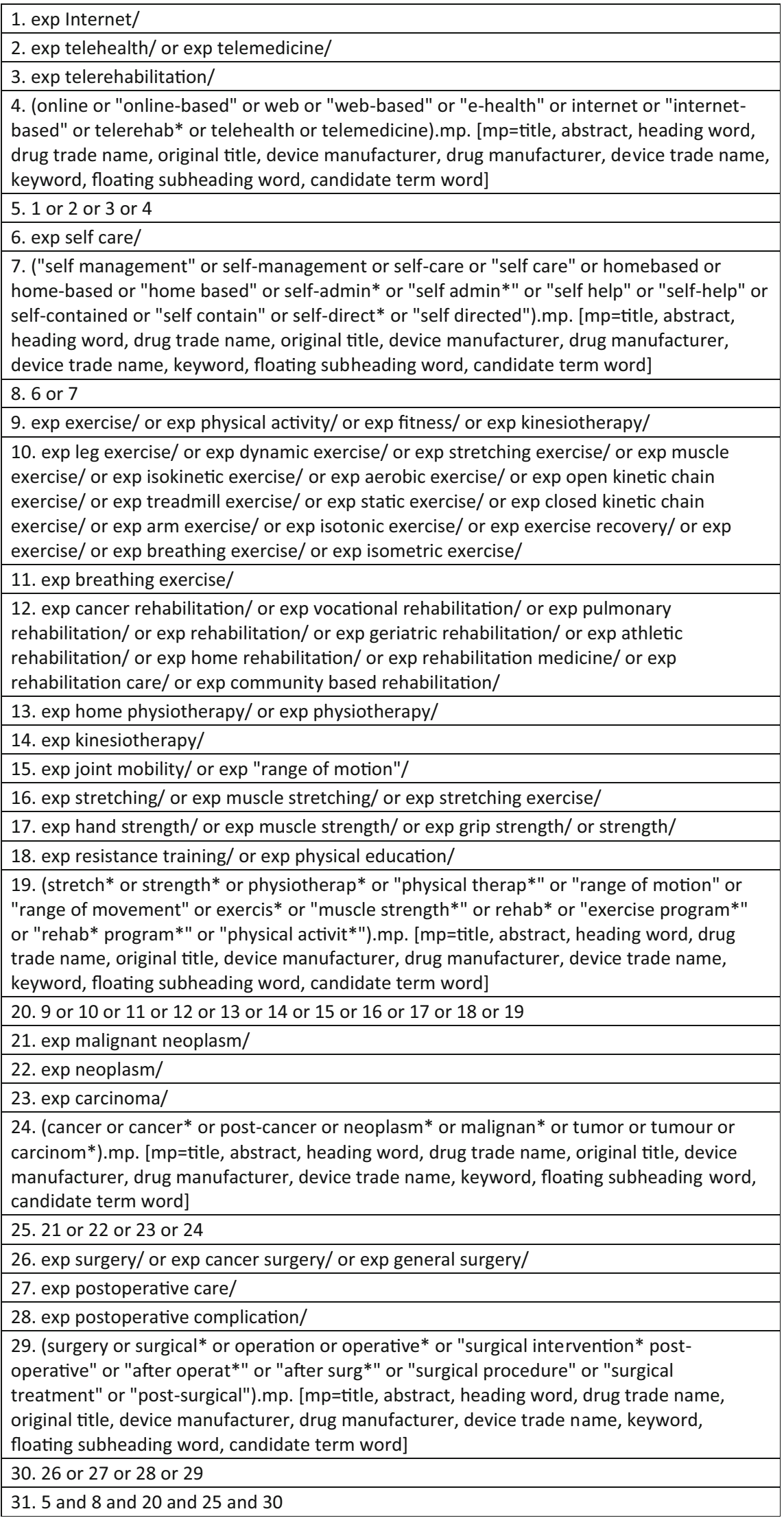

Fig. 1 OVID-EMBASE search strategy 
Table 1 Search terms, concepts and medical headings

\begin{tabular}{|c|c|c|}
\hline Search concepts & Keywords & $\mathrm{MeSH}$ \\
\hline 1) Internet & $\begin{array}{l}\text { Internet or "Internet-based" or online or } \\
\text { "online-based" or web or "web-based" } \\
\text { or "e-health" or comput* or PC or website } \\
\text { or mobile or ehealth or mhealth or "m-health" } \\
\text { or telemedicine or telehealth or telerehab* } \\
\text { or teletherap* }\end{array}$ & $\begin{array}{l}\text { Internet } \\
\text { E-health } \\
\text { Telerehabilitation } \\
\text { Telehealth } \\
\text { Telemedicine }\end{array}$ \\
\hline 2) Self-management & $\begin{array}{l}\text { "self management" or self-management or self-care } \\
\text { or "self care" or homebased or home-based or } \\
\text { "home based" or self-admin* or "self admin*" } \\
\text { or "self help" or "self-help" or self-contained } \\
\text { or "self contain" or self-direct* or "self directed" }\end{array}$ & $\begin{array}{l}\text { Self-care } \\
\text { Self-management } \\
\text { "Self-directed learning as topic" }\end{array}$ \\
\hline 3) exercise & $\begin{array}{l}\text { stretch* or strength* or physiotherap* or "physical } \\
\text { therap*" or "range of motion" or "range of } \\
\text { movement" or exercis* or "muscle strength*" } \\
\text { or rehab* or "exercise program*" or "rehab } \\
\text { program*" or exercise or "physical activit*" }\end{array}$ & $\begin{array}{l}\text { Exercise therapy } \\
\text { Physical therapy } \\
\text { Rehabilitation } \\
\text { Physical activity/exercise } \\
\text { Muscle stretching exercises } \\
\text { Resistance training } \\
\text { Range of motion, articular } \\
\text { Activities of daily living } \\
\text { Early ambulation }\end{array}$ \\
\hline 4) Cancer & $\begin{array}{l}\text { cancer or cancer* or post-cancer or neoplasm* or } \\
\text { malignan* or tumour or carcinom* or oncolog* }\end{array}$ & $\begin{array}{l}\text { Neoplasms } \\
\text { Carcinoma }\end{array}$ \\
\hline 5) Surgery & $\begin{array}{l}\text { surgery OR surgical* OR operation OR operative* } \\
\text { OR "surgical intervention" OR "postoperative" OR } \\
\text { "after operat*" OR "after surg*" OR "surgical } \\
\text { procedure" OR "surgical treatment" OR “post-surgical" }\end{array}$ & $\begin{array}{l}\text { General surgery } \\
\text { Postoperative complications/ } \\
\text { surgical procedures, operative/ } \\
\text { surgery, operative and } \\
\text { postoperative care }\end{array}$ \\
\hline 6) Response to intervention & $\begin{array}{l}\text { accept* or adher* or barrier* or facilitat* or preference* } \\
\text { or reaction or satisfact* or uptake or usab* }\end{array}$ & $\begin{array}{l}\text { Treatment adherence and compliance, } \\
\text { personal satisfaction, patient } \\
\text { acceptance of healthcare, health } \\
\text { knowledge, attitudes, practice, } \\
\text { patient preference, patient attitude }\end{array}$ \\
\hline
\end{tabular}

\section{Internet interventions}

Bennett and Glasgow [25] define these as "Systematic treatment/prevention programs, usually addressing one or more determinants of health (frequent health behaviours), delivered largely via the Internet (although not necessarily exclusively Web-based), and interfacing with an end user. These interventions are typically highly structured, mostly self-guided, interactive, and visually rich, and they may provide tailored messaging based on end-user data".

\section{Adherence to a treatment modality}

Adherence has been defined by Kelders and colleagues [26] as "The extent to which the patient's behaviour matches the recommendations that have been agreed upon with the prescriber". According to the definition we used and as per the context of this definition provided by its authors, "the patient's behaviour" is considered the usage or the absence of usage of the intervention and whether or not it matches the intended intervention usage that is recommended by the intervention creators [26].

\section{Treatment acceptability}

Sekhon and colleagues [27] define acceptability as "A multifaceted construct that reflects the extent to which people delivering or receiving a healthcare intervention consider it to be appropriate, based on anticipated or experienced cognitive and emotional responses to the intervention". For the purposes of this article, this definition describes emotional or cognitive responses to an intervention that may or may not involve usage of the intervention. As per the given context of this definition by its authors, it includes the users' perceptions of treatment acceptability for both: before and as a result of participating or using a treatment intervention [27].

\section{User satisfaction with web-based health interventions}

Bob and colleagues [28] define user satisfaction with web-based health interventions as "Satisfaction is a user's evaluation of the 
Fig. 2 Study selection process with exclusion reasons
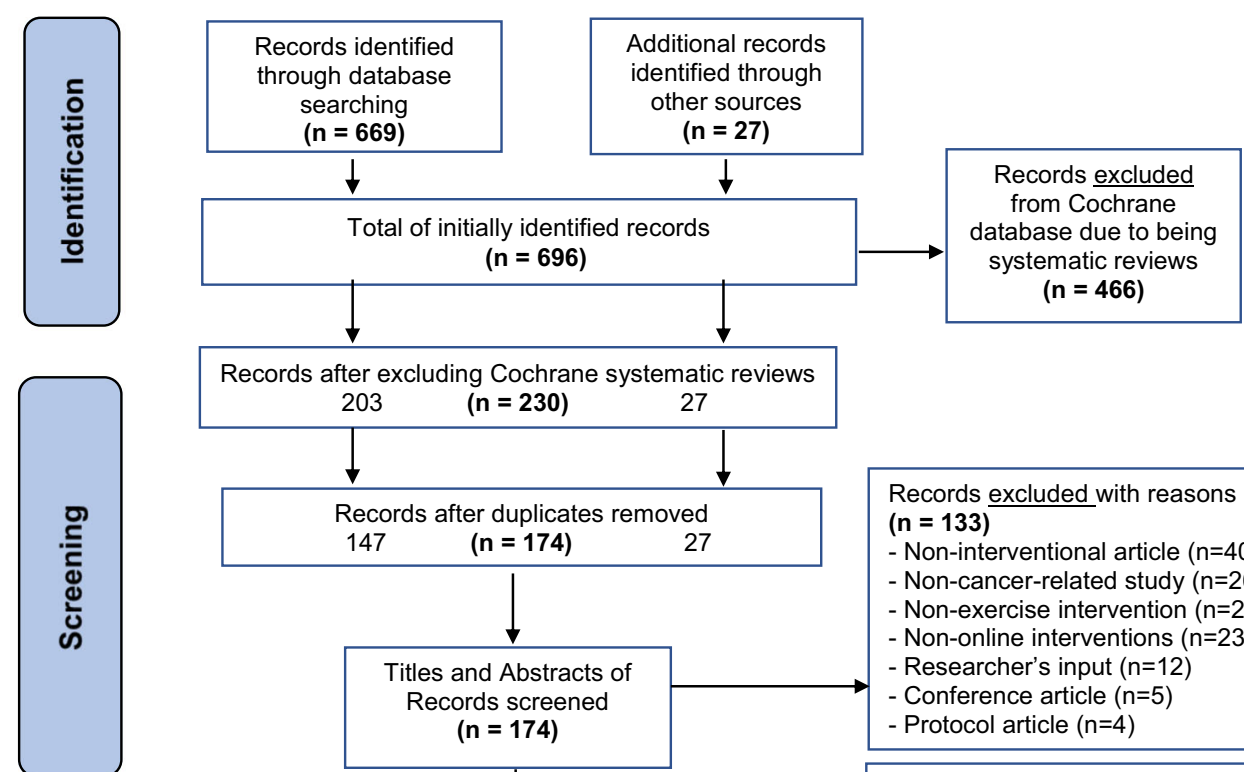

Records excluded with reasons ( $n=133$ )

- Non-interventional article $(n=40)$

- Non-cancer-related study $(n=26)$

- Non-exercise intervention $(n=23)$

- Non-online interventions $(n=23$

- Researcher's input $(n=12)$

- Conference article $(n=5)$

- Protocol article $(n=4)$

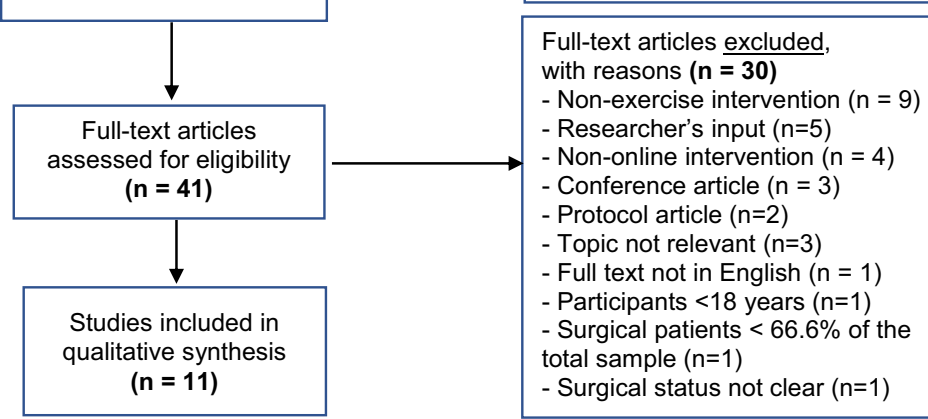

received Web-based intervention". For the purposes of this article, the definition for satisfaction does not describe, and therefore distinguishes itself, from the emotional or cognitive reaction to an intervention. This definition only describes the evaluation processes that the intervention users might undergo during or after intervention usage in order to approve or disapprove a given intervention [28].

\section{Self-management interventions}

"Interventions that aim to equip patients with skills to actively participate and take responsibility in the management of their chronic condition. This includes knowledge acquisition, and a combination of at least two of the following: (1) stimulation of independent sign and/or symptom monitoring; (2) medication management; (3) enhancing problem-solving and decisionmaking skills for treatment or disease management; (4) or changing physical activity, dietary and/or smoking behaviour" [29].

\section{Data extraction and methodological quality assessment}

Predefined data extraction tables were used to summarize study designs and main characteristics (Table 2), participant characteristics (Table 3), types and features of interventions (Table 4) and the main study findings (Table 5). Methodological quality was assessed using the standard quality assessment criteria for evaluating primary research papers from a variety of fields by Kmet and colleagues [30] which consists of two separate quality assessment scales for qualitative and quantitative studies (Tables 6 and 7). The quality of the studies was rated according to the scoring that Lee et al. [31] and Maharaj and Harding [32] used in their similarly designed reviews. Study quality was rated according to accepted scoring methods and cutoffs with summary scores $>80 \%$ defined as "strong", $71-79 \%$ as good, $50-70 \%$ as adequate, and scores of $<50 \%$ indicating "poor" or limited quality. Data extraction and quality assessment were conducted by at least two independent reviewers (MS and IW or LR) and inter-rater level of agreement between the reviewers was evaluated using Cohen's kappa [33] and Cohen's weighted kappa values [34]. Studies were not excluded from the synthesis based on quality scores, which were used to interpret the findings of the review.

\section{Analysis and synthesis of the results}

A narrative approach [35] was used to synthesize study characteristics and key findings of the included evidence. The 
Table 2 General characteristics of the included studies

\begin{tabular}{|c|c|c|c|}
\hline Study/author/year/country & Study aims & Study design & Data collection tools \\
\hline $\begin{array}{l}\text { Cnossen et al. (2016) [43] } \\
\text { The Netherlands }\end{array}$ & $\begin{array}{l}\text { Aim: To explore the } \\
\text { feasibility of a self-care } \\
\text { education programme, } \\
\text { by measuring } \\
\text { intervention usage, } \\
\text { uptake and the end-user } \\
\text { satisfaction, in addition } \\
\text { to secondary care }\end{array}$ & $\begin{array}{l}\text { Quantitative study } \\
\text { A single-group } \\
\text { cross-sectional } \\
\text { feasibility and } \\
\text { satisfaction study design }\end{array}$ & $\begin{array}{l}\text { Study-specific survey } \\
\text { 10-point Likert scale } \\
\text { A study-specific } \\
\quad \text { questionnaire }\end{array}$ \\
\hline $\begin{array}{l}\text { Foster et al. (2016) [38] } \\
\text { United Kingdom }\end{array}$ & $\begin{array}{l}\text { Aim: To assess the proof of } \\
\text { concept of the } \\
\text { RESTORE web-based } \\
\text { intervention }\end{array}$ & $\begin{array}{l}\text { Mixed-methods study } \\
\text { A multicentre } \\
\text { parallel-group } \\
\text { two-armed } \\
\text { exploratory randomized } \\
\text { controlled trial with } \\
\text { qualitative process } \\
\text { evaluation }\end{array}$ & $\begin{array}{l}\text { Semi-structured telephone } \\
\text { interviews } \\
\text { Data usage } \\
\text { Questionnaires }\end{array}$ \\
\hline $\begin{array}{l}\text { Harder et al. (2017) [44] } \\
\text { United Kingdom }\end{array}$ & $\begin{array}{l}\text { Aim: To present the } \\
\text { development process } \\
\text { of the bWell app and the } \\
\text { preliminary results of } \\
\text { early user testing }\end{array}$ & $\begin{array}{l}\text { Qualitative focus group } \\
\text { study with preliminary } \\
\text { user testing }\end{array}$ & Focus group discussions \\
\hline $\begin{array}{l}\text { Kanera et al. (2016) [39] } \\
\text { The Netherlands }\end{array}$ & $\begin{array}{l}\text { Aim: To assess the effects } \\
\text { of the web-based life } \\
\text { after cancer (KNW) } \\
\text { intervention on the } \\
\text { outcomes: physical } \\
\text { activity, diet and } \\
\text { smoking } 6 \text { months after } \\
\text { using the KNW } \\
\text { intervention }\end{array}$ & $\begin{array}{l}\text { Quantitative study } \\
\text { A } \\
\text { randomized controlled trial }\end{array}$ & $\begin{array}{l}\text { Online self-report } \\
\text { questionnaires } \\
\text { Data usage } \\
\text { Login data }\end{array}$ \\
\hline $\begin{array}{l}\text { Kanera et al. (2017) [36] } \\
\text { The Netherlands }\end{array}$ & $\begin{array}{l}\text { Aim: To assess the } \\
\text { long-term effects of the } \\
\text { web-based life after } \\
\text { cancer (KNW) } \\
\text { intervention on the } \\
\text { outcomes for moderate } \\
\text { physical activity and } \\
\text { vegetable consumption } \\
\text { at } 12 \text { months after using } \\
\text { the KNW intervention in } \\
\text { order to track } \\
\text { maintenance of these } 2 \\
\text { outcomes between } \\
6 \text { months post baseline } \\
\text { and } 12 \text { months }\end{array}$ & $\begin{array}{l}\text { Quantitative study } \\
\text { A } \\
\text { randomized controlled trial }\end{array}$ & $\begin{array}{l}\text { Online self-report } \\
\text { questionnaires } \\
\text { Data usage } \\
\text { Login data }\end{array}$ \\
\hline $\begin{array}{l}\text { Lee et al. (2013) [46] } \\
\text { Republic of Korea }\end{array}$ & $\begin{array}{l}\text { Aim: To design and } \\
\text { develop a web-based } \\
\text { self-management diet } \\
\text { and exercise intervention } \\
\text { for cancer survivors } \\
\text { which is based on the } \\
\text { trans-theoretical model } \\
\text { and to formally evaluate } \\
\text { the intervention }\end{array}$ & $\begin{array}{l}\text { A mixed-method } \\
\text { qualitative and } \\
\text { quantitative intervention } \\
\text { development and formal } \\
\text { evaluation study }\end{array}$ & $\begin{array}{l}\text { Qualitative semi-structured } \\
\text { interviews } \\
\text { Questionnaires with } \\
\text { 7-point scale } \\
\text { Intervention usage }\end{array}$ \\
\hline $\begin{array}{l}\text { Lee et al. (2014) [40] } \\
\text { South Korea }\end{array}$ & $\begin{array}{l}\text { Aim: To investigate if the } \\
\text { web-based } \\
\text { self-management } \\
\text { exercise and diet } \\
\text { intervention (WSEDI) } \\
\text { for breast cancer } \\
\text { survivors based on the } \\
\text { trans-theoretical model }\end{array}$ & $\begin{array}{l}\text { Quantitative study } \\
\text { A 12-week pilot } \\
\text { randomized controlled } \\
\text { trial with a control group }\end{array}$ & $\begin{array}{l}\text { Self-reported online } \\
\quad \text { surveys } \\
\text { 7-day exercise diary } \\
\text { 3-day dietary recall } \\
\text { Cancer-specific } \\
\text { questionnaires } \\
\text { Intervention usage }\end{array}$ \\
\hline
\end{tabular}


Table 2 (continued)

\begin{tabular}{|c|c|c|c|}
\hline Study/author/year/country & Study aims & Study design & Data collection tools \\
\hline \multirow{3}{*}{$\begin{array}{l}\text { Melissant et al. (2018) [41] } \\
\text { The Netherlands }\end{array}$} & $\begin{array}{l}\text { is feasible and having a } \\
\text { primary effect on } \\
\text { improving the quality of } \\
\text { dietary behaviours and } \\
\text { exercising. }\end{array}$ & & \\
\hline & Aim: To evaluate the & Quantitative study & Semi-structured interviews \\
\hline & $\begin{array}{l}\text { feasibility of the } \\
\text { Oncokompas } \\
\text { intervention among } \\
\text { breast cancer survivors, } \\
\text { featuring the breast } \\
\text { cancer module }\end{array}$ & $\begin{array}{l}\text { A pre-test-post-test } \\
\text { feasibility study }\end{array}$ & $\begin{array}{l}\text { Pre- and post-intervention } \\
\text { surveys } \\
\text { Consultation with } \\
\text { oncology nurse } \\
\text { Intervention usage }\end{array}$ \\
\hline $\begin{array}{l}\text { Myall et al. (2015) [45] } \\
\text { United Kingdom }\end{array}$ & $\begin{array}{l}\text { Aim: To explore the } \\
\text { amount of work that the } \\
\text { participants in the RCT } \\
\text { related to this } \\
\text { intervention were } \\
\text { required to do }\end{array}$ & $\begin{array}{l}\text { An in-depth qualitative } \\
\text { process evaluation study }\end{array}$ & $\begin{array}{l}\text { Semi-structured telephone } \\
\text { interviews }\end{array}$ \\
\hline Paxton et al. (2017) [42] & $\operatorname{Aim}(s)$ & Quantitative study & Web-based survey \\
\hline United States & $\begin{array}{l}\text { 1. To investigate if } \\
\text { participants from the } \\
\text { physical activity (PA) } \\
\text { group would have } \\
\text { greater improved } \\
\text { moderate to physical } \\
\text { activity level than those } \\
\text { participants randomized } \\
\text { in the Dietary group } \\
\text { 2. To investigate if } \\
\text { participants from the } \\
\text { dietary group would } \\
\text { have greater improved } \\
\text { fruit and vegetable } \\
\text { consumption than those } \\
\text { participants randomized } \\
\text { in the PA group }\end{array}$ & $\begin{array}{l}\text { A randomized } \\
\text { parallel-group feasibility } \\
\text { study }\end{array}$ & $\begin{array}{l}\text { consisting of 5-point } \\
\text { Likert scaled questions } \\
\text { Web-based survey: a } \\
\text { yes/no question } \\
\text { Web-based survey with } \\
\text { open-ended questions } \\
\text { Website usage tracking }\end{array}$ \\
\hline Willems et al. (2017) [37] & Aim: To present the & Quantitative study & Self-report questionnaires \\
\hline The Netherlands & $\begin{array}{l}\text { short-term effects of the } \\
\text { KNW intervention on } \\
\text { QoL, anxiety, } \\
\text { depression and fatigue }\end{array}$ & $\begin{array}{l}\text { A randomized controlled } \\
\text { trial }\end{array}$ & Modules usage \\
\hline
\end{tabular}

included studies were categorized and agreed on as quantitative, qualitative or mixed-methods studies by two of the reviewers, based on the study design definitions presented by the study authors and on the type of their quantitative, qualitative or mixed findings [35].

\section{Results}

A total of 696 records were identified and 41 underwent fulltext review. Eleven studies published between 2013 and 2018 and with a total sample size $(n=965)$ met the study inclusion criteria and were included in the synthesis. Five studies were conducted in the Netherlands, three in the United Kingdom, two in South Korea and one in the United States. There were three randomized controlled trials (RCTs) which were presented in five different studies [36-40] (with predominantly quantitative study designs [36, 37, 39, 40] and one mixedmethods RCT and process evaluation study [38]), three feasibility studies, all with quantitative study designs [41-43], one qualitative early user testing study [44] and two evaluation studies [45, 46] that had qualitative [45] and mixed-methods [46] study designs. The studies with quantitative designs that constituted the majority of all studies in this review $(n=7)$ used single-group feasibility design [43], an RCT [36, 37, 39], a pilot RCT [40], a pre- and post-test feasibility study [41] and a randomized parallel-group feasibility study [42]. The two studies with the entirely qualitative designs and 


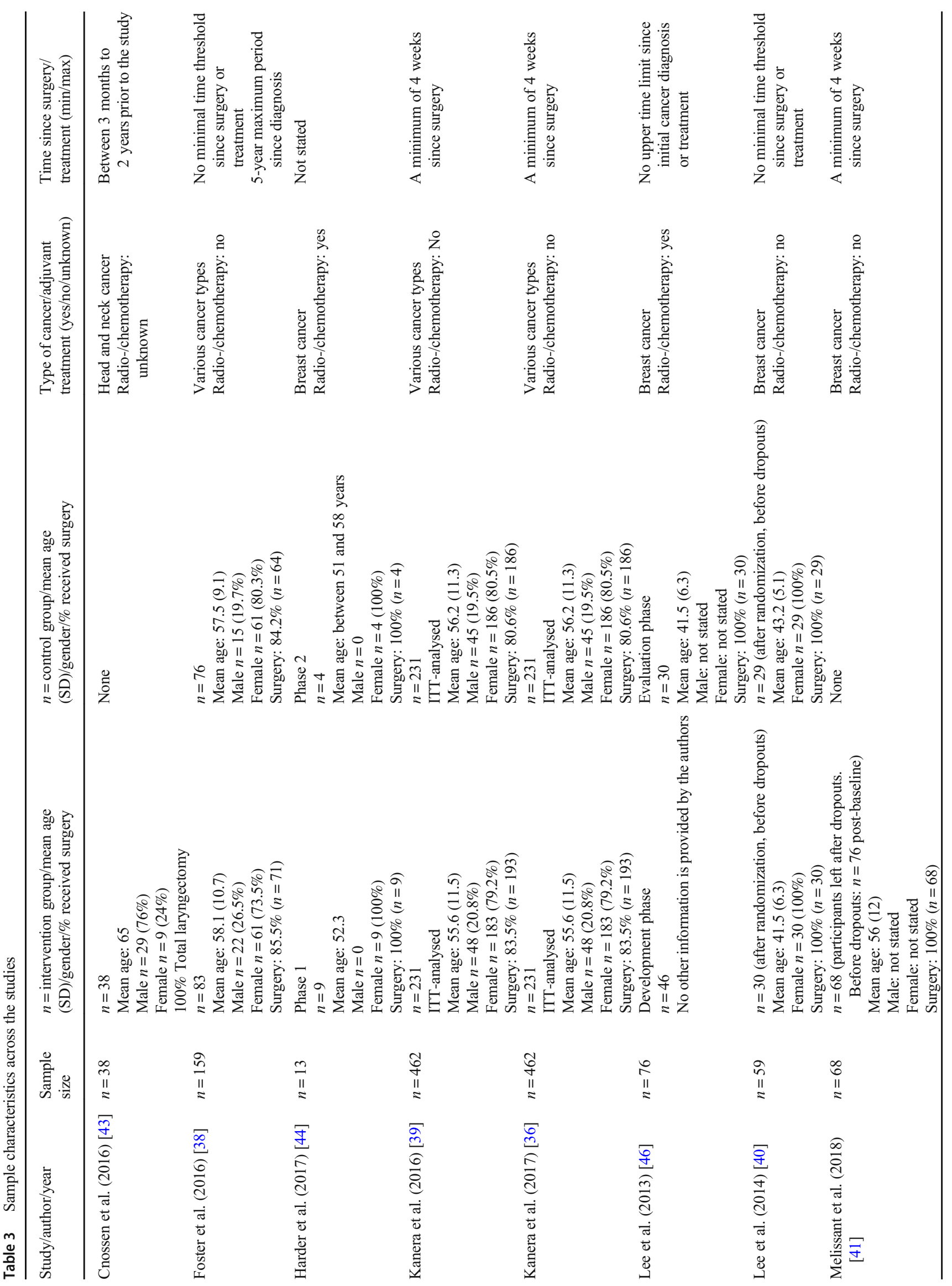




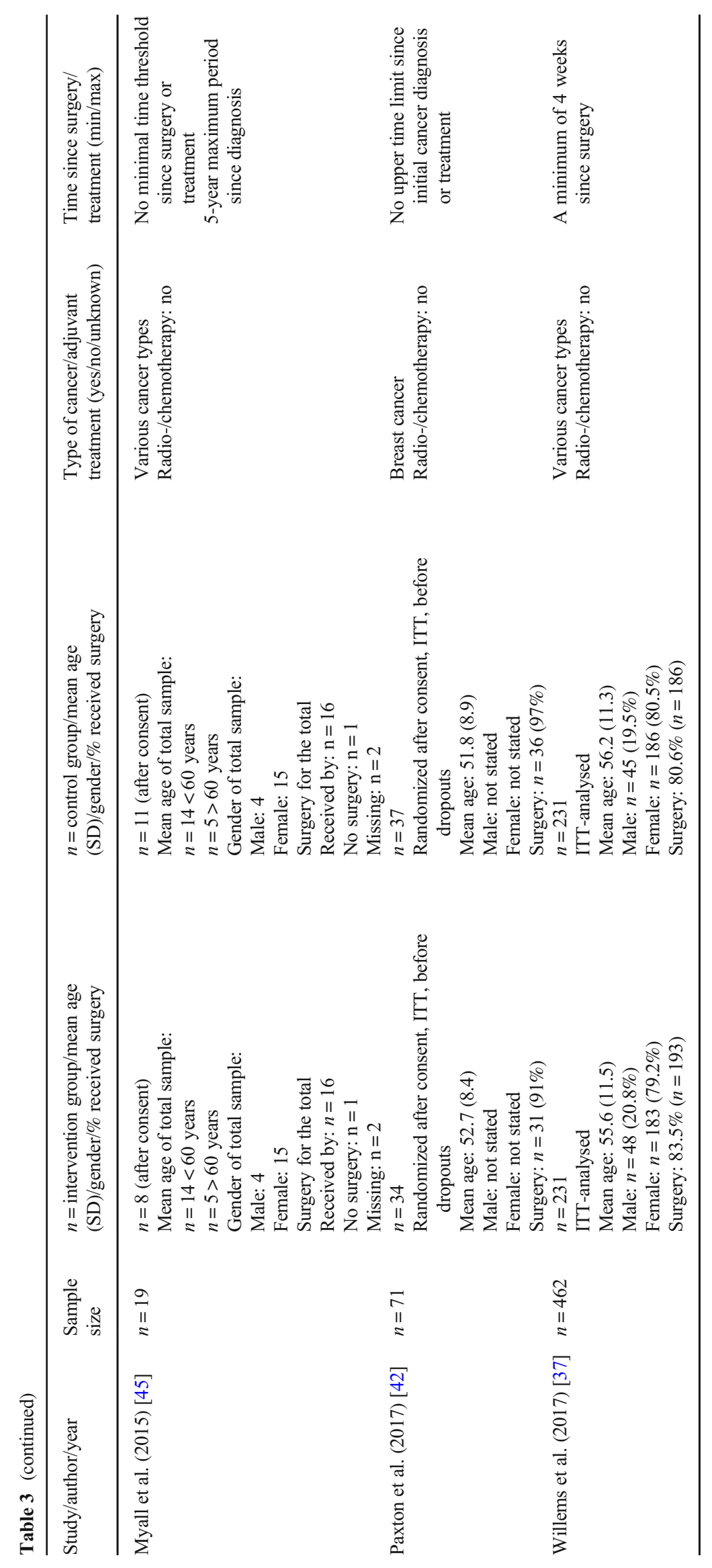




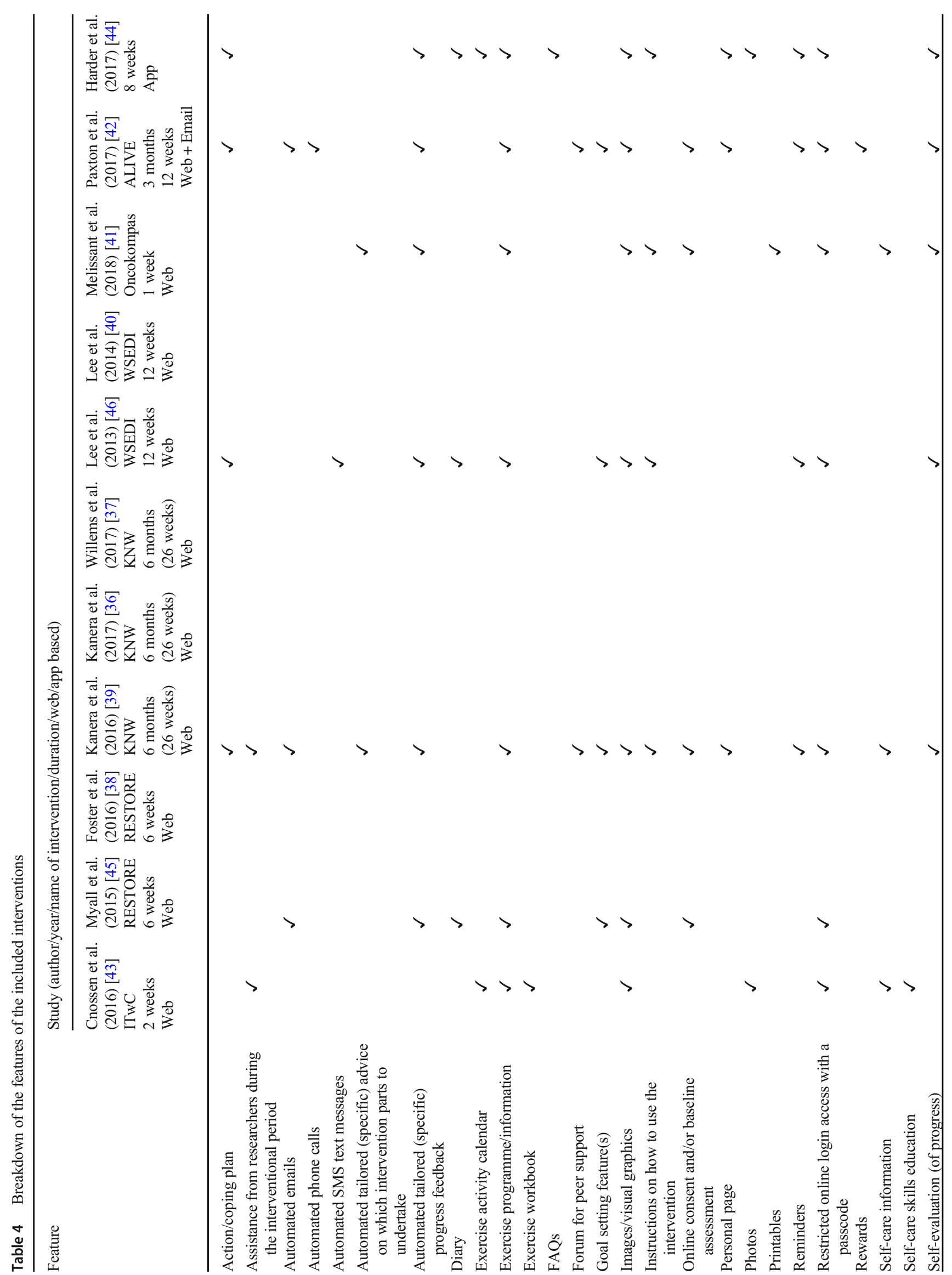




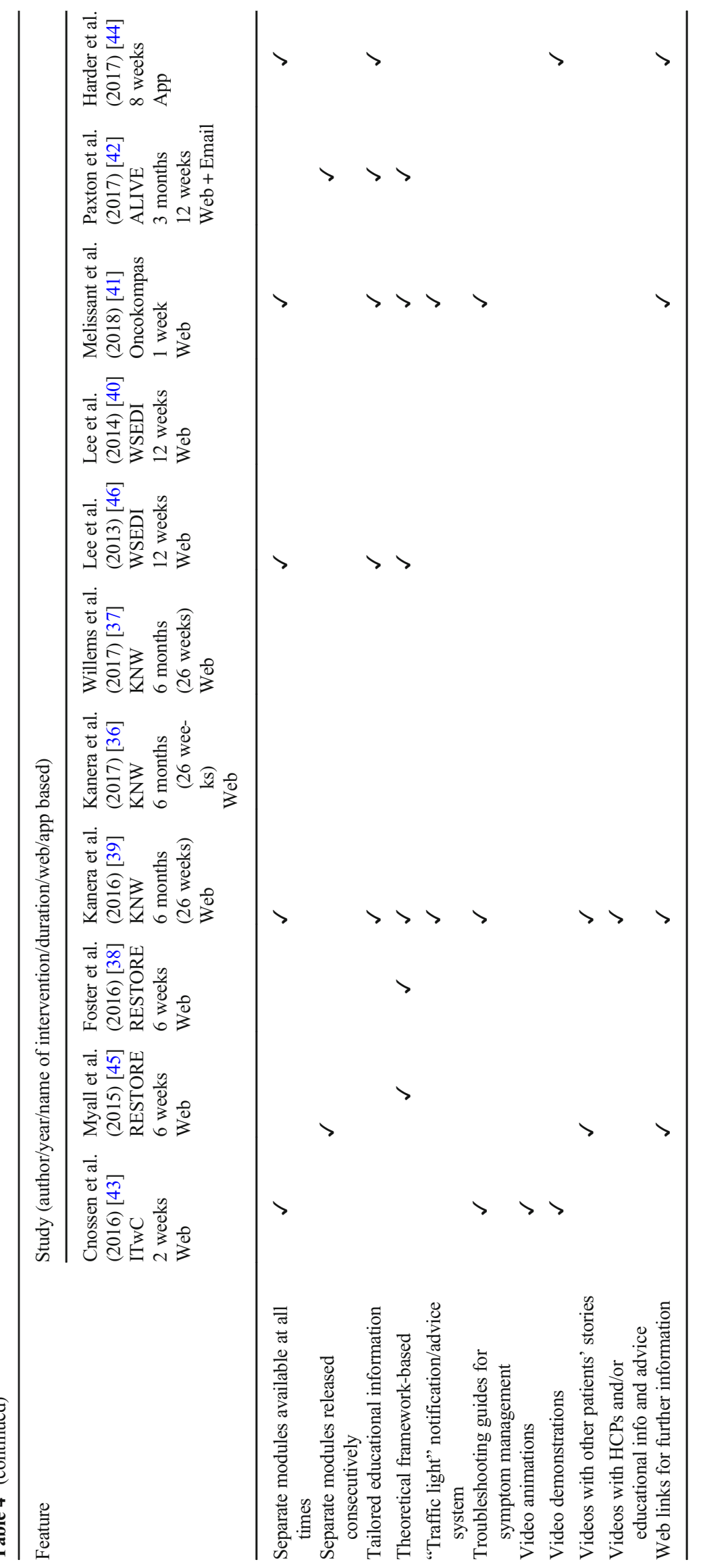



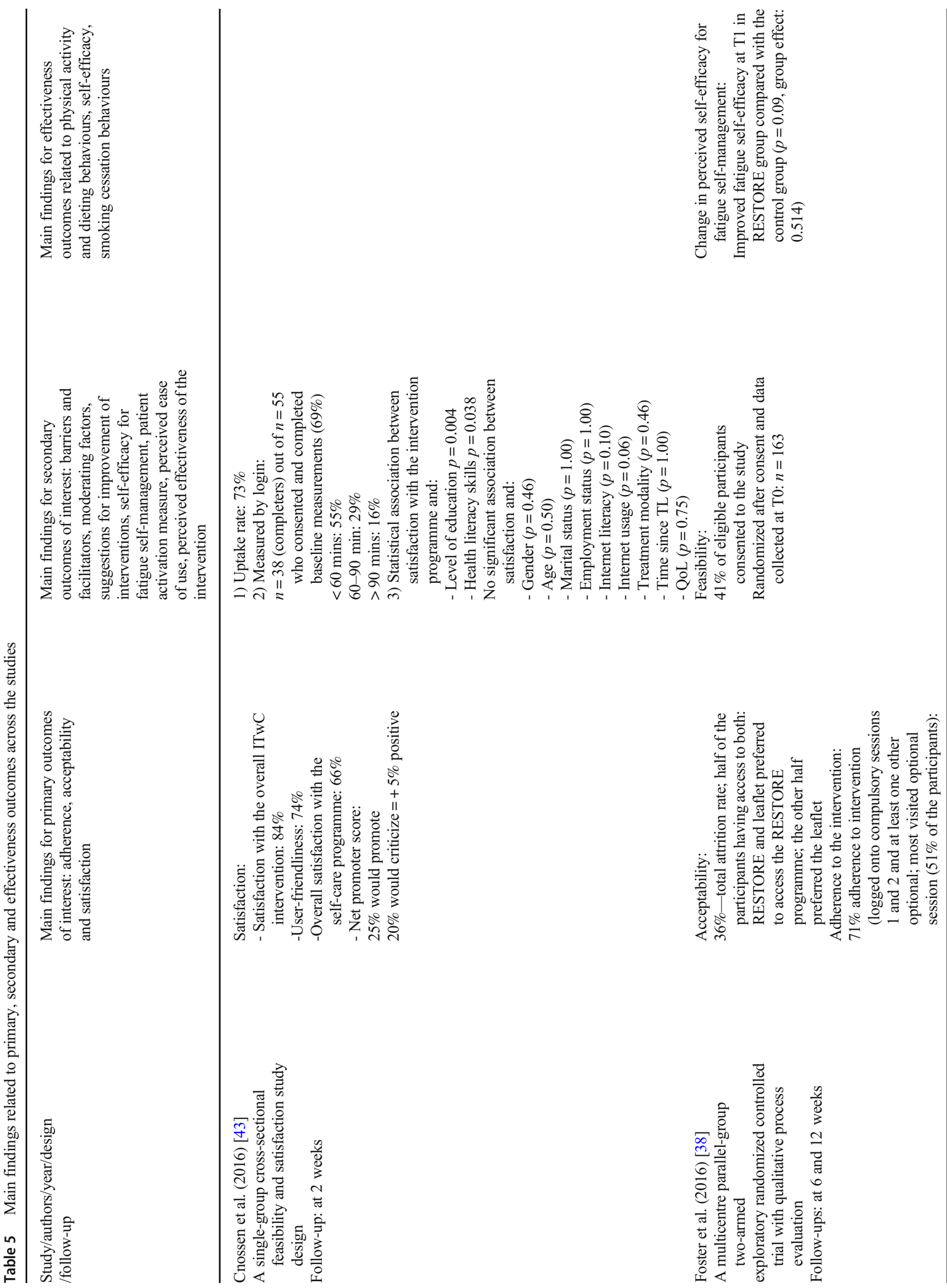

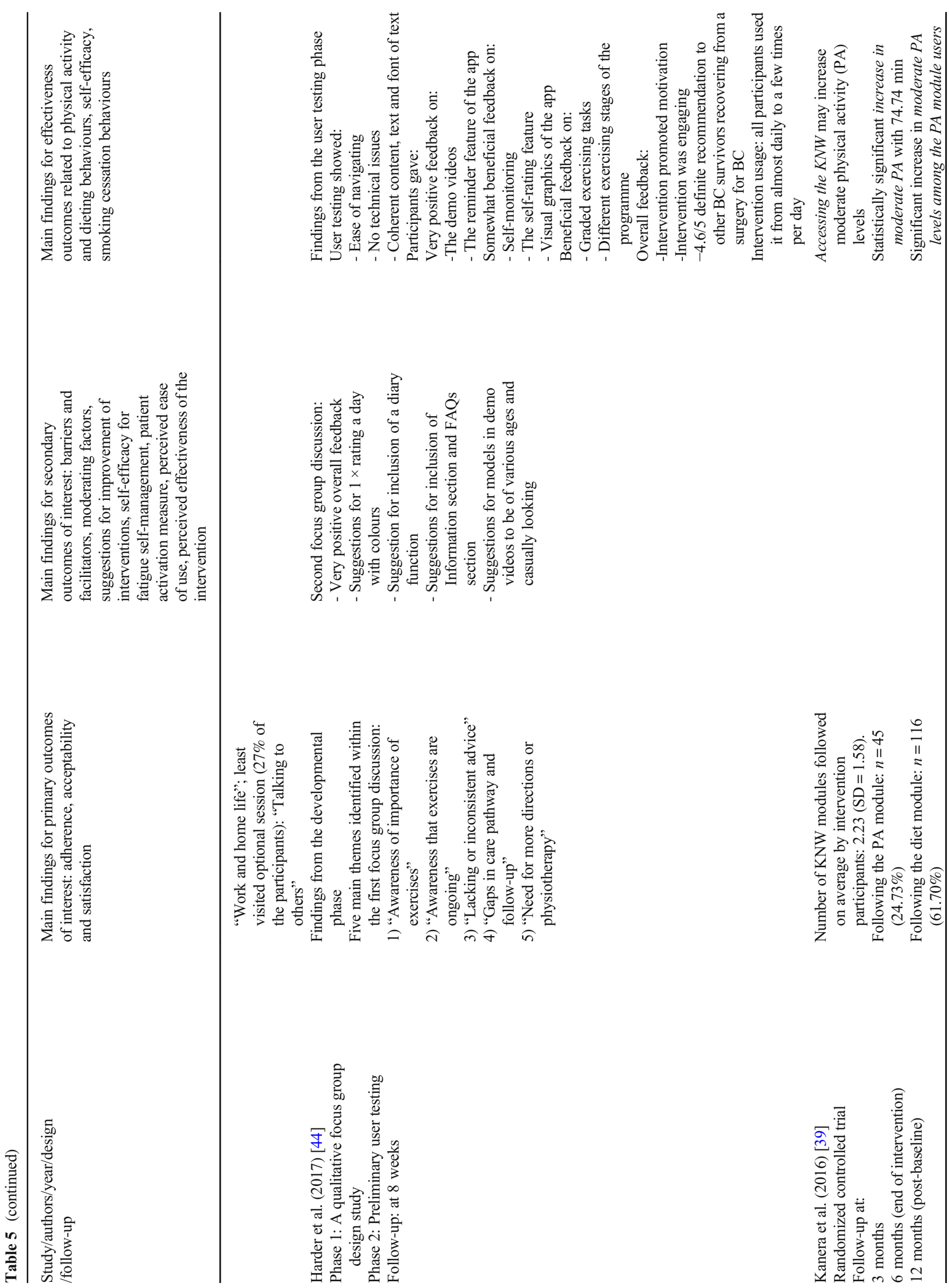


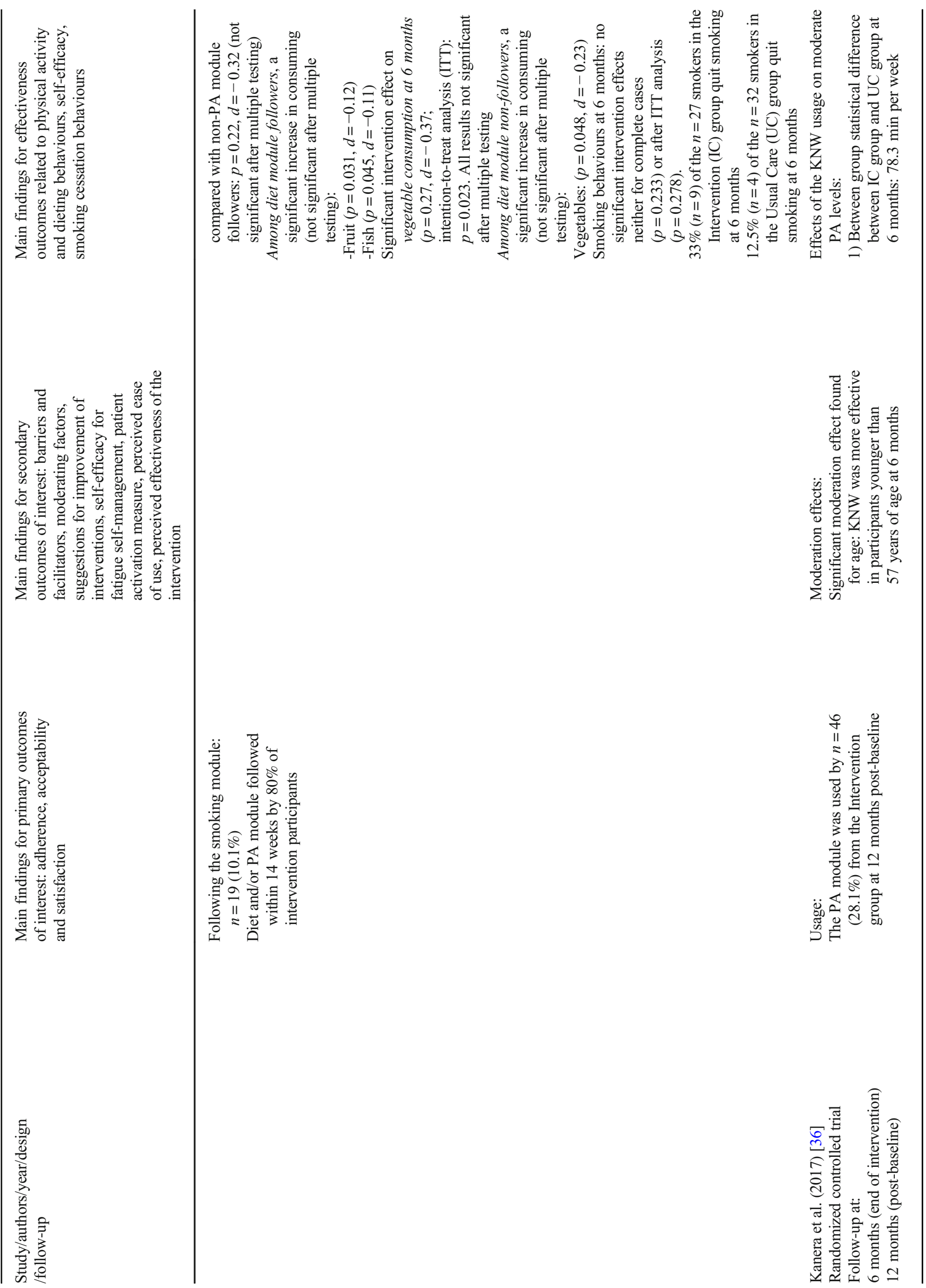




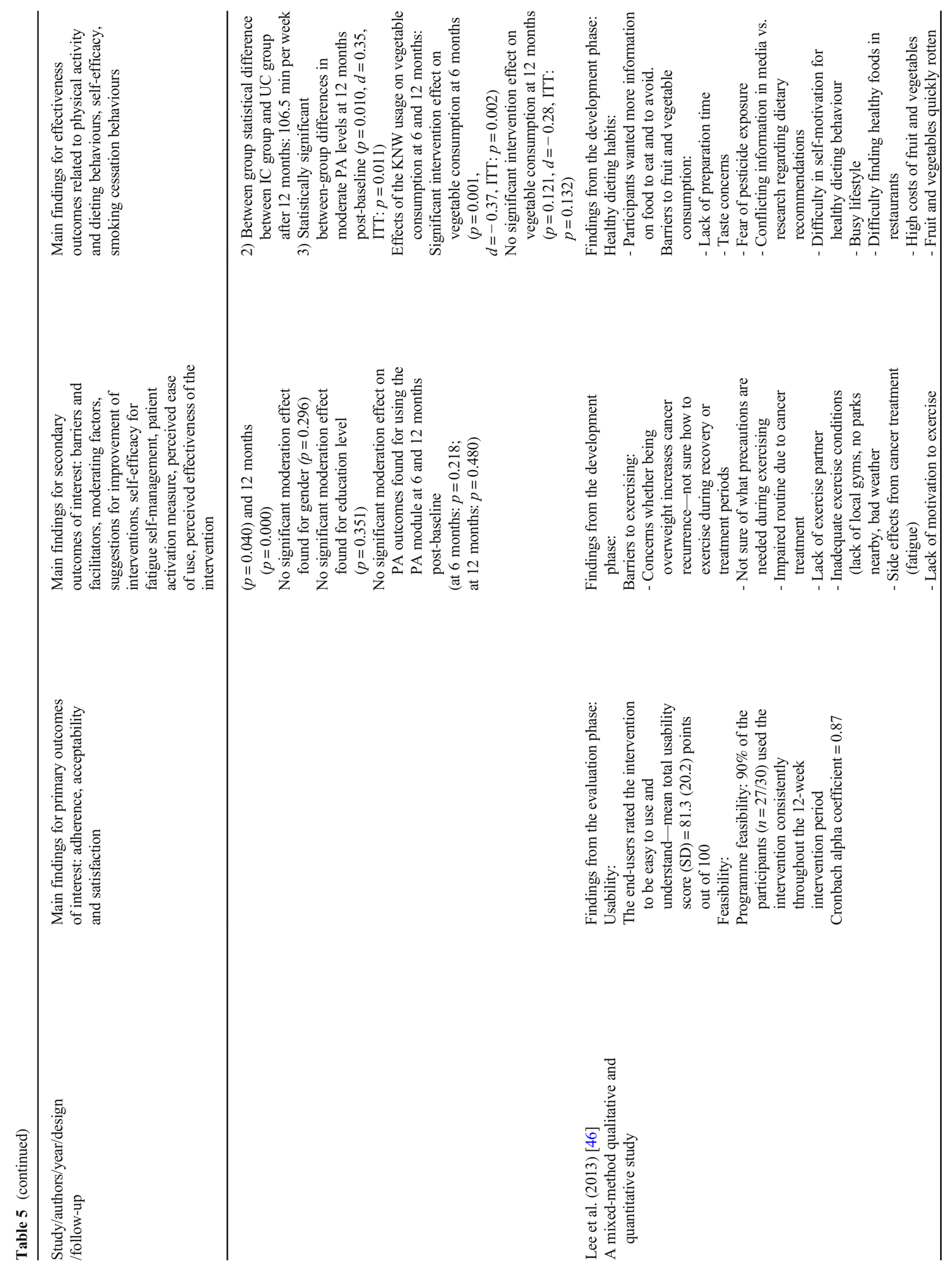



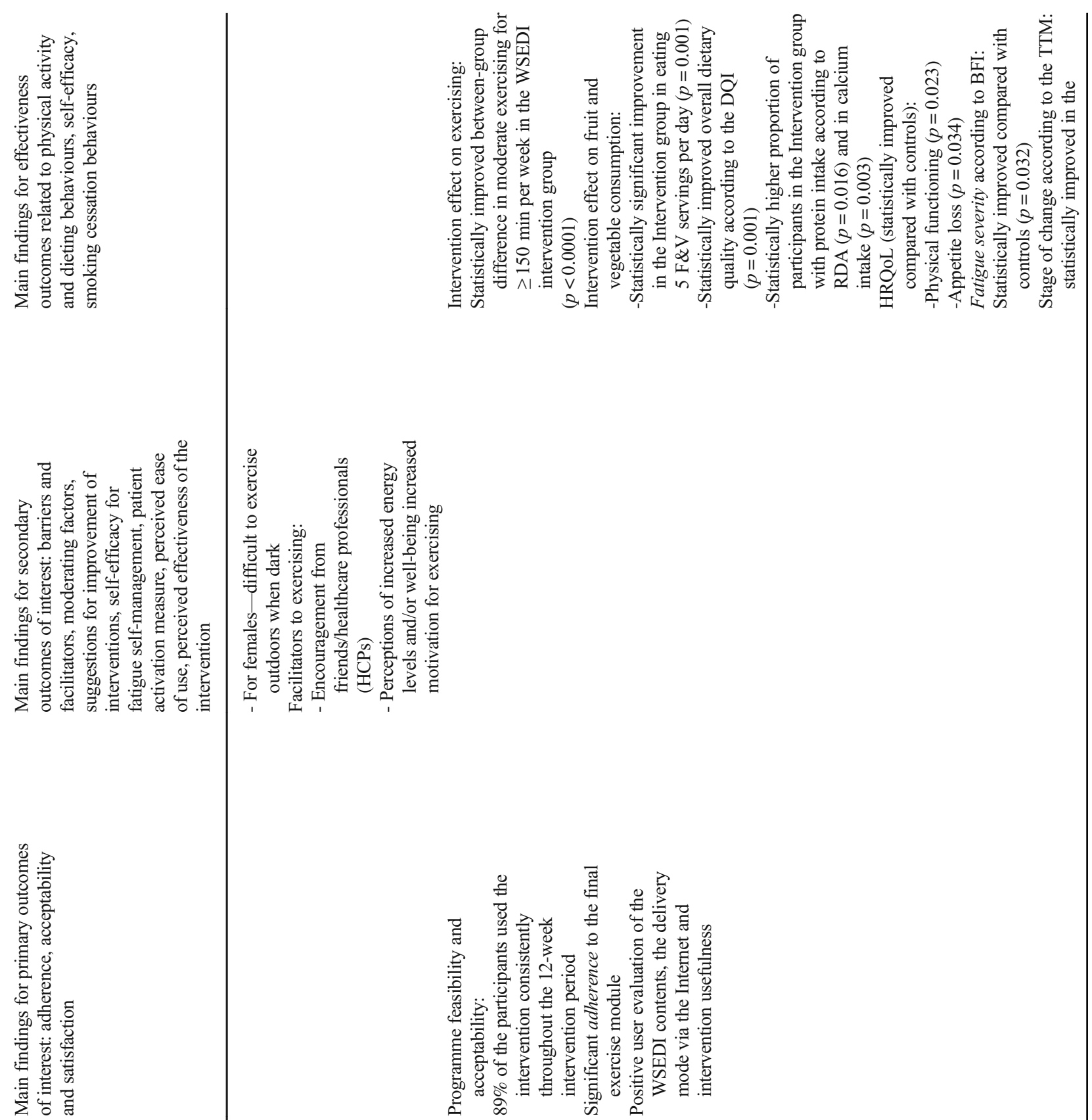

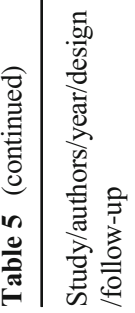

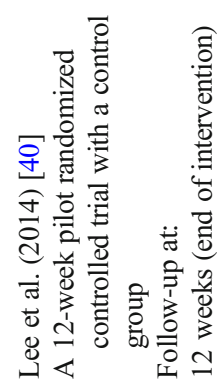



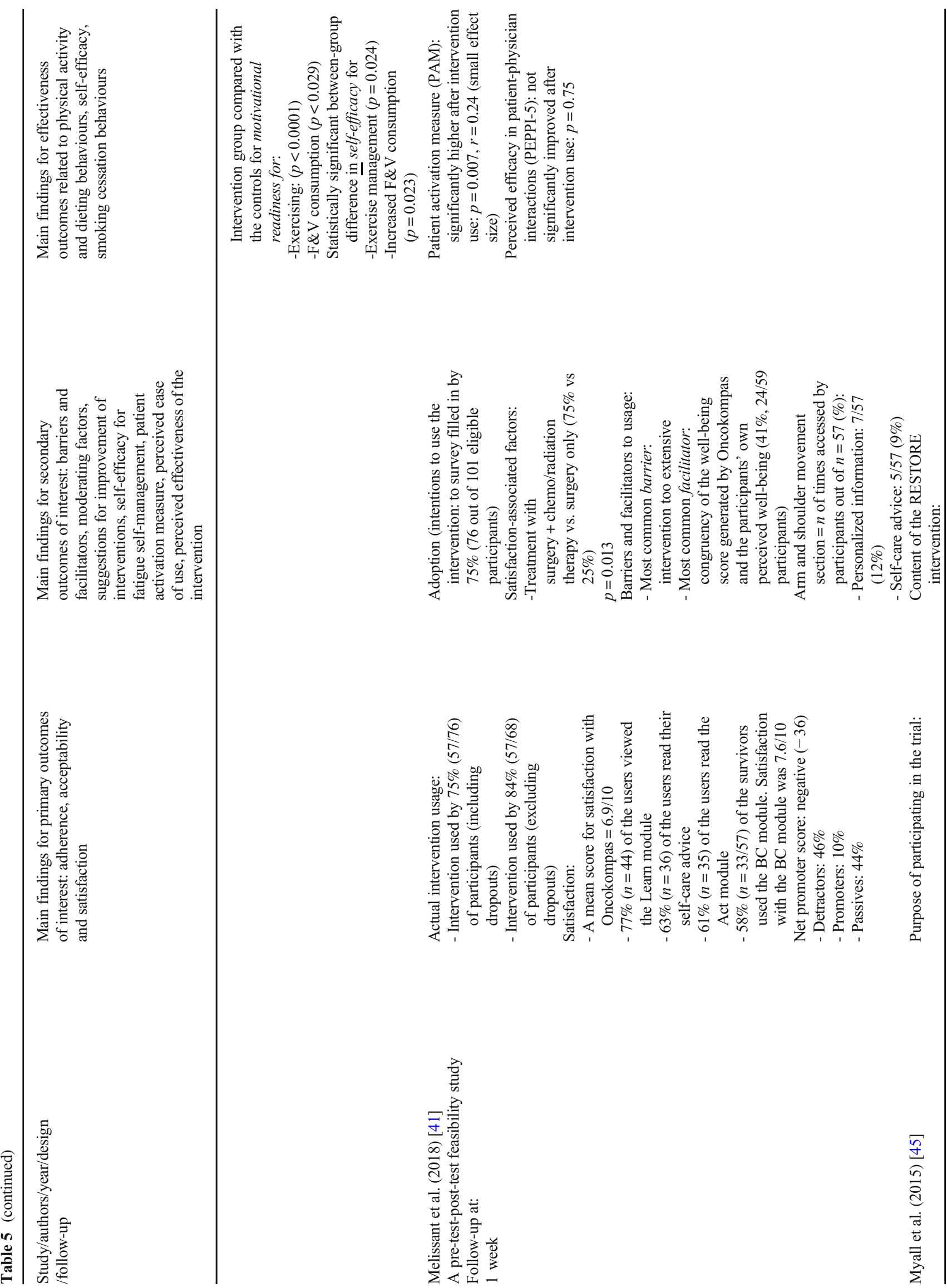

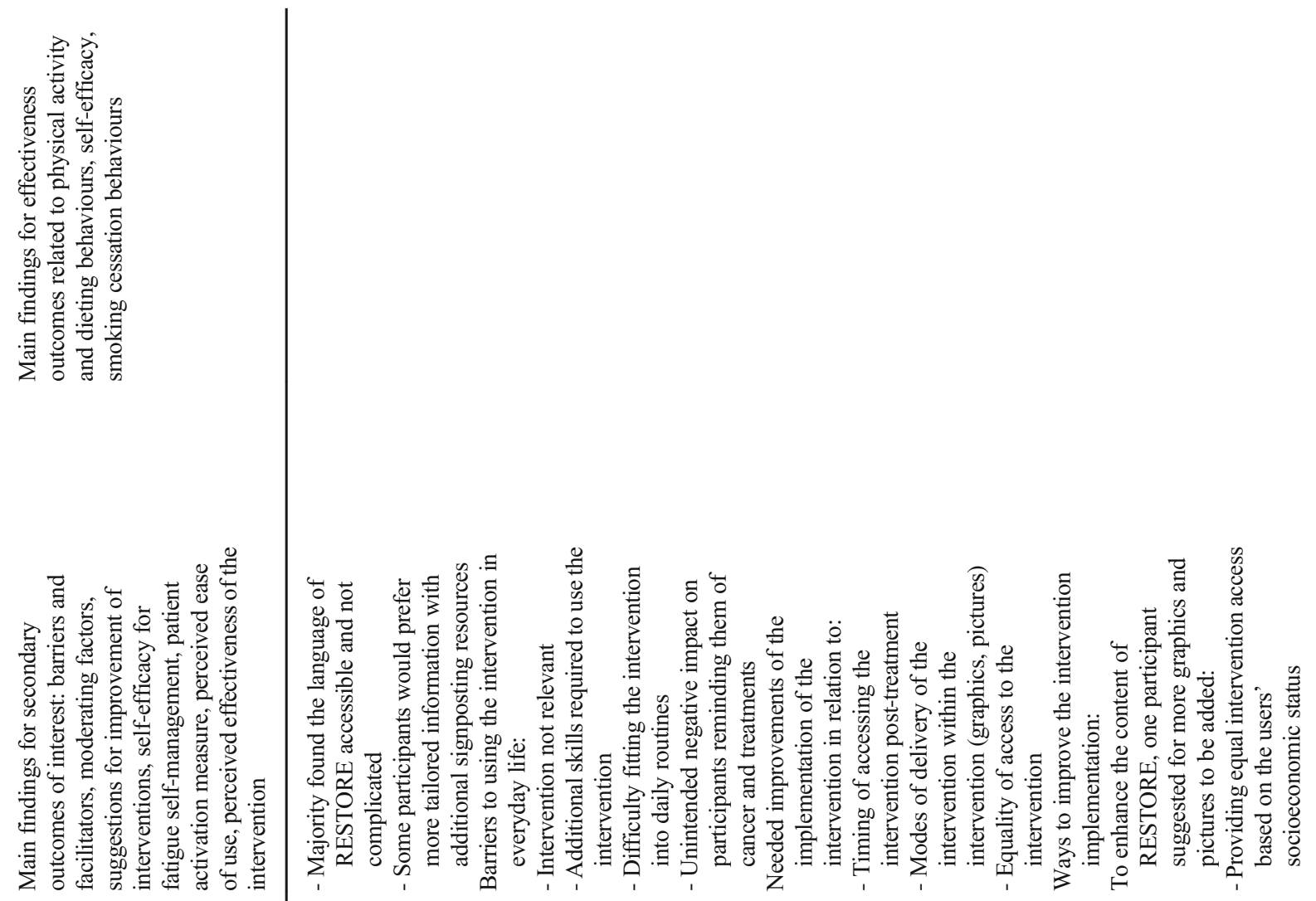

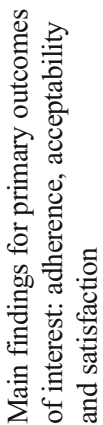

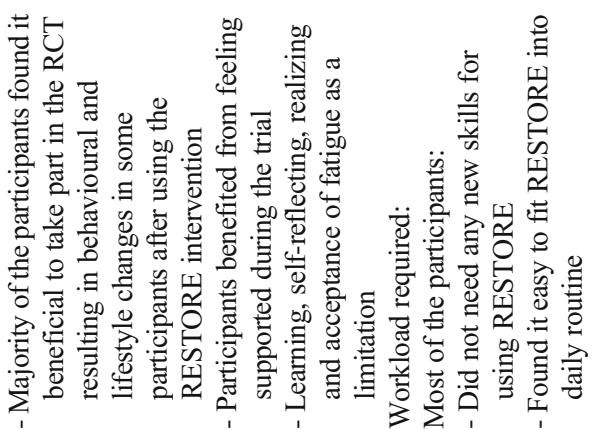

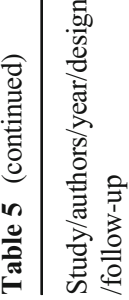

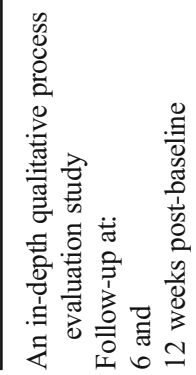



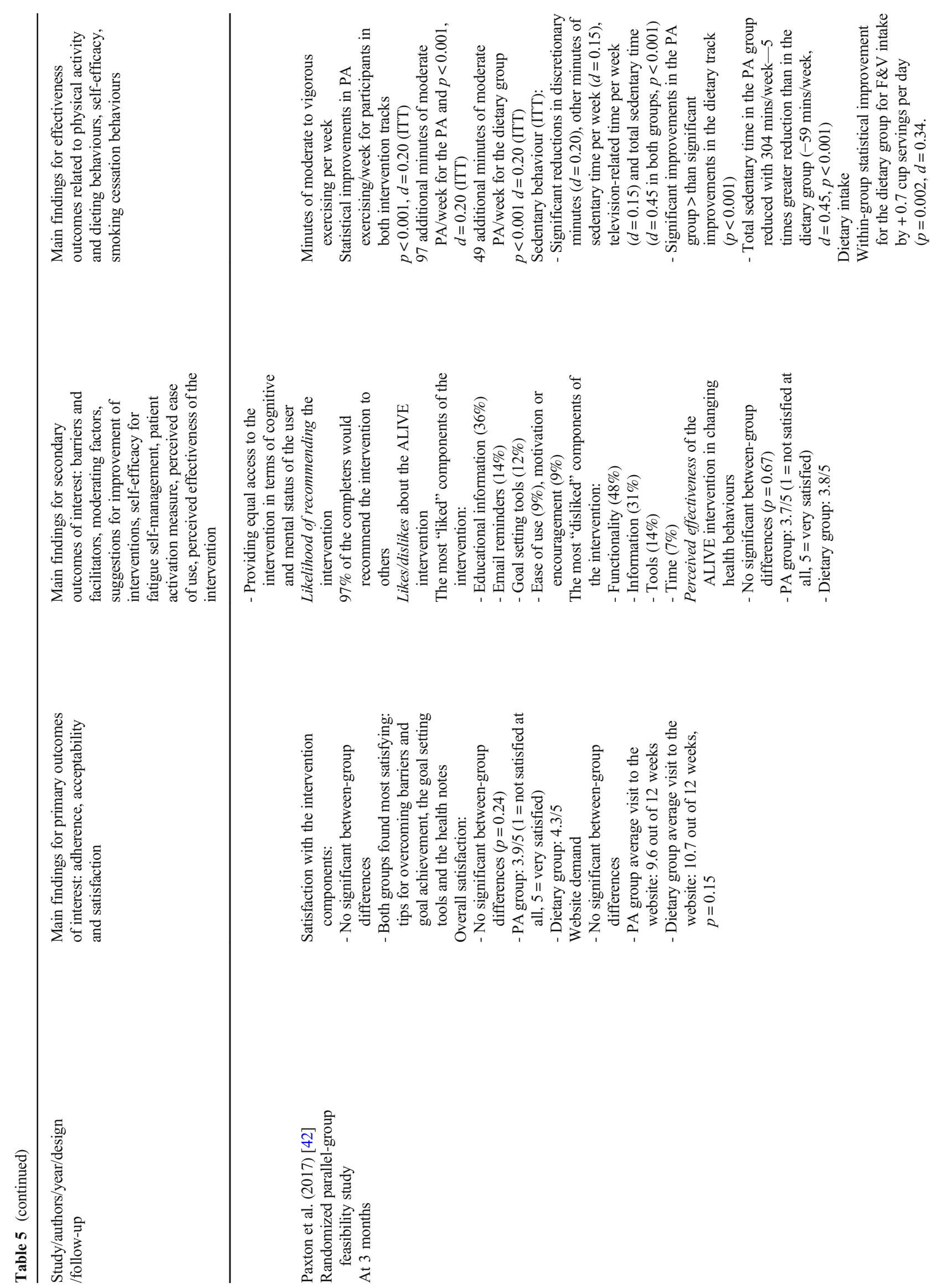

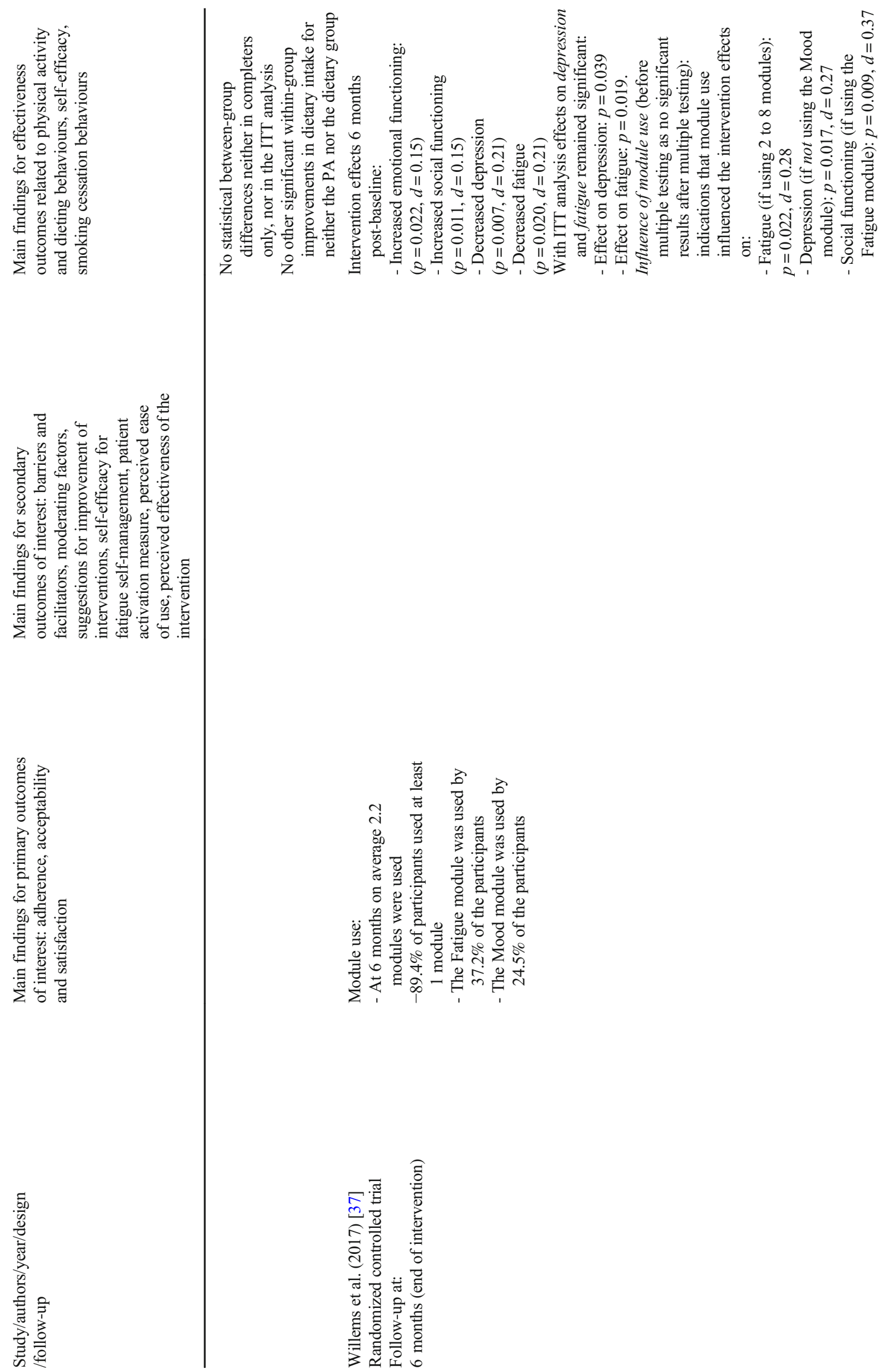


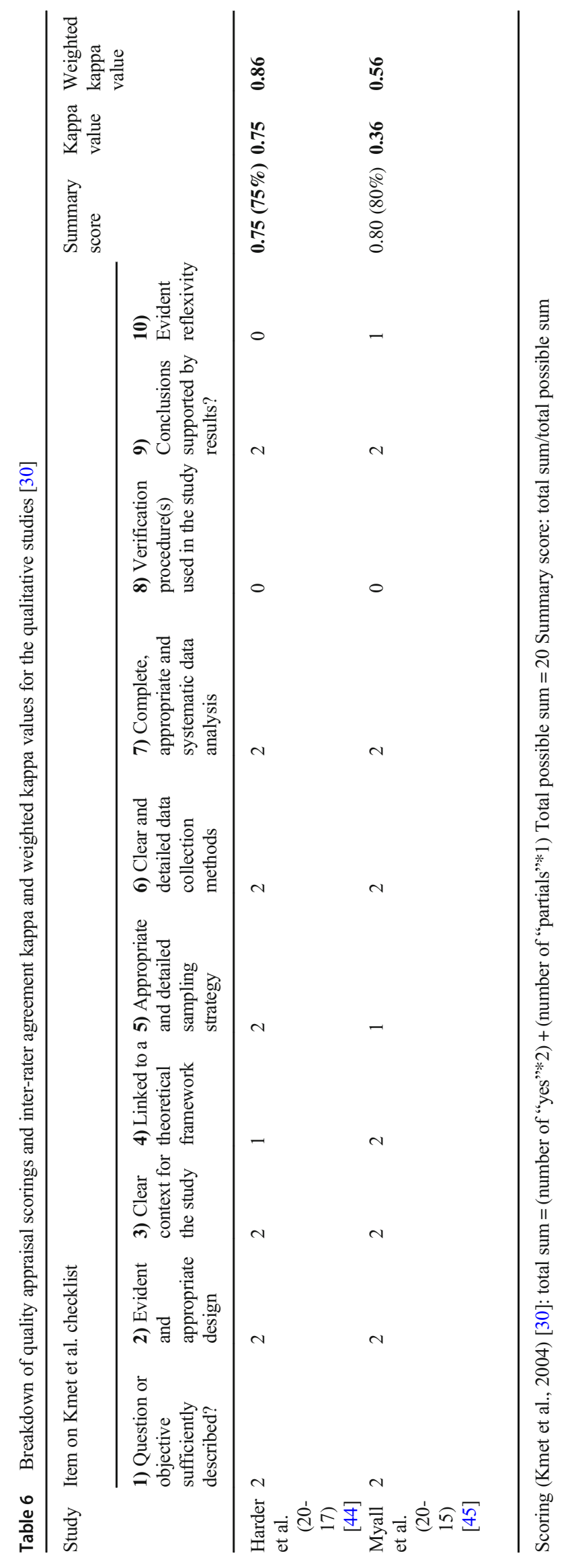




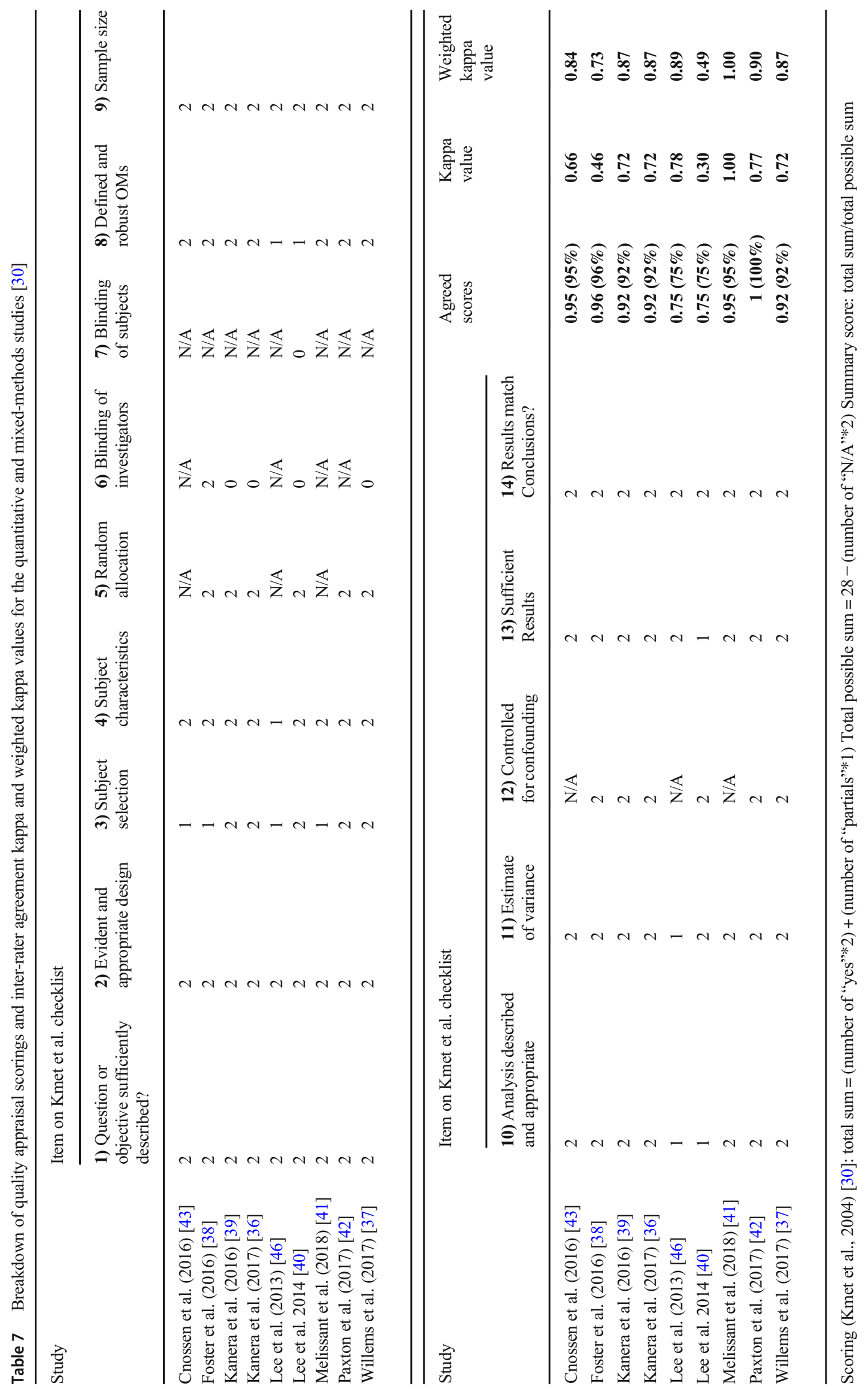


qualitative findings [44, 45] were conducted using focus groups [44] and in-depth interviews [45] for the purposes of conducting qualitative testing [44] and an evaluation [45] of their interventions. The two studies that adopted mixed quantitative and qualitative methodologies $[38,46]$ conducted process [38] and formative [46] evaluations and, hence, provided both types of data, with prevailing quantitative data in them.

The most commonly used tools for quantitative data collection across the studies were study-specific surveys or questionnaires, validated outcome-specific tools which occasionally were adapted and/or translated into the participants' language, semi-structured telephone interviews, data usage, standard questionnaires and self-reported questionnaires. The collection of qualitative data was mainly performed using telephone interviews, open-ended questions and an evaluation survey. Lee et al. [46] in their study used qualitative semi-structured interviews to obtain their qualitative data during the intervention development and questionnaires with 7-point scales in order to obtain quantitative data for process evaluation.

\section{Demographic characteristics of included studies}

Sample sizes (total $n=965$ ) varied greatly: from 13 participants in one qualitative study [44] to 462 participants in a randomized controlled trial (RCT) described in three articles $[36,37,39]$. The sample size range within the qualitative studies $[44,45]$ was much smaller $(N=13$ and $N=19$, respectively) than the sample sizes in the studies with quantitative designs. However, even within the studies with quantitative designs, variations depending on the type of study were noted. The three quantitative feasibility studies [41-43] had relatively smaller sample sizes of $N=68, N=71$ and $N=38$, compared with the significantly larger sample sizes within the RCT studies with samples of $N=462[36,37,39]$ and $N=$ 159 [38]. Noticeably, the pilot RCT study by Lee and colleagues [40] also had a relatively small sample size $(N=59)$ compared with the other RCTs included in this review.

Participants across seven out of the 11 articles (described in detail in Table 3) were predominantly females (Median: 80\%, IQR: $20 \%$ ), with two studies [40,44] having entirely female populations. The only study with a male majority of participants was by Cnossen et al. [43], where $76 \%$ were men. Three articles $[41,42,46]$ did not explicitly report the gender of their participants. Participants across all featured studies had a mean age of 53.2 years with the youngest participants with a mean age of 41.5 years [46] and with the oldest participants' mean age of 65 years [43].

The most prevalent type of cancer diagnosis that the participants had was BC. In five out of 11 studies [40-42, 44, 46], all participants had $\mathrm{BC}$ and received various types of breast surgeries (see Table 3). Only one study [43] had participants who all had a cancer different to BC (laryngeal cancer) and they received head and neck (HAN) surgery. The studies by Foster et al. [38] and by Myall et al. [45] included participants with, respectively, seven and five differing types of cancers (with the relevant surgeries). $\mathrm{BC}$ was again the most prevalent one. Kanera et al. [36], Kanera et al. [39] and Willems et al. [37] reported on the same RCT participant sample, the majority $(70.5 \%)$ of whom had BC. Four studies $[36,37,39,41]$ had imposed a minimum of 4 weeks since surgery or other treatment as inclusion criterion. Three studies [38, 40, 45] had no minimal time threshold since surgery or treatment. Paxton et al. [42] and Lee et al. [46] had no upper time limit since initial cancer diagnosis or treatment, whereas Foster et al. [38] and Myall et al. [45] set a 5-year maximum period since diagnosis for inclusion. All participants, except for those in the studies by Harder et al. [44] and Lee et al. [46], were not receiving or had completed radiotherapy and/or chemotherapy treatments. Cnossen et al. [43] did not exclude the presence of radiotherapy and/or chemotherapy treatments but did not report participants undergoing such treatment.

\section{Intervention characteristics}

The 11 articles analysed in this review described seven individual interventions: (1) Cnossen and colleagues [43] described the "In Tune without Cords" (ITwC) intervention; (2) Foster et al. [38] and Myall et al. [45] described the RESTORE intervention; (3) Harder and colleagues [44] described the bWell app intervention; (4) the Kanker Nazorg Wijzer (KNW) intervention or, in English, the "Cancer Aftercare Guide" intervention was reported by Kanera and colleagues [36, 39] and by Willems and colleagues [37]; (5) Lee and colleagues $[40,46]$ described the web-based selfmanagement exercise and diet intervention (WSEDI); (6) Melissant et al. [41] described the Oncokompas intervention; (7) Paxton et al. [42] described the ALIVE intervention. These seven interventions described across 11 articles included five web-based interventions described in nine articles [36-41, 43, $45,46]$, a mobile app [44] and an intervention sent by email and web-based [42]. Four out of the 11 selected articles reported on their own individual interventions [41-44]. Four studies had no comparator group and were single-group studies $[41,43,44,46]$. Three studies adopted usual care as their comparator intervention [36, 37, 39], whereas three studies compared their online intervention to using a leaflet [38, 40, 45] and one study [42] had two interventional groups and compared the uptake of the two different "tracks" of their intervention.

Each of the seven interventions in this review addressed a range of different domains as follows: (1) Cnossen et al. [43] (nutrition; tracheostomy care; voice prosthesis care; speech rehabilitation; smell rehabilitation; and mobility of the head, neck and shoulder muscles); (2) Foster et al. [38] and Myall et al. [45] (cancer-related fatigue, goal setting, diet, sleep, 
exercise, addressing issues around home and work life; thoughts and feelings; and talking to others); (3) Harder et al. [44] (self-management of arm and shoulder exercises); (4) Kanera et al. [36, 39] and Willems et al. [37] (physical activity, diet, smoking cessation, return to work, fatigue, anxiety and depression, social relationship and intimacy issues and general information on the most common residual symptoms of cancer); (5) Lee et al. [40, 46] (self-management of exercise and diet); (6) Melissant et al. [41] (endocrine therapy, (early) menopausal symptoms, body image, fertility issues, hereditary breast cancer, lymphoedema, fibrosis, armshoulder movement, breast reconstruction, breast prosthesis and sexuality); and (7) Paxton et al. [42] (behaviour change regarding physical activity or diet).

All interventions but one [44] were Internet web-based and participants accessed these via a web browser. Only the intervention by Harder et al. [44] was a downloadable mobile application. The intervention periods varied: the shortest being 1 week for intervention usage [41] and the longest being 6 months described by Kenara et al. [36, 39] and by Willems et al. [37]. The most common intervention duration was 12 weeks long, which was noted across the two interventions by Lee et al. [40, 46] and by Paxton et al. [42].

Topic-wise, one intervention aimed to raise participants' general awareness and knowledge about cancer, its treatment and supportive services [41] and another intervention [43] provided specific advice about laryngeal cancer and its aftermath. Harder et al. [44] designed their intervention specifically for upper limb exercising after BC surgery. The single intervention "RESTORE" that was written up in the two studies by Myall et al. [45] and by Foster et al. [38] was specifically about coping with fatigue. The most common combination of topic modules was about a healthier diet and increased levels of physical activity (PA) included across two of the interventions by Kenara et al. [36, 37, 39] and by Lee et al. $[40,46]$. Table 4 presents a breakdown of all the features of the interventions across the studies and their duration.

Table 4 presents a breakdown of the intervention features. Many of the articles reported common intervention features, for instance, all interventions included password-restricted login access, specific or non-specific exercise programmes or advice and images and visual graphics. All but one [43] offered automated and individually tailored progress feedback notifying the intervention user of achieved goals and selfregulation purposes while using the interventions; for instance, they provided personalized feedback on dietary behaviours, as per pre-set goals in the intervention by Kanera et al. [36, 39]/Willems et al. [37]. The two interventions described by Foster et al. [38]/Myall et al. [45] and by Cnossen et al. [43] did not offer tailored educational information and online selfevaluation of progress, unlike the other interventions in this review. The offered tailored educational information was usually provided by automated personalization of the information for advice and educational purposes, depending on the user information provided prior to or during using the intervention and aiming to correspond to their needs, for instance, the tumour-specific $\mathrm{BC}$ educational information for intervention users who have had BC [41]. The features for self-evaluation of progress while using the intervention were usually tools allowing self-ticking options for self-monitoring purposes within the intervention [42] or for self-reporting to the research team web-based progress outcomes in the form of surveys [ $[40,46]$. Other features were printable results [41], automated phone calls with a coaching session and achievement rewards [42], automated telephone text messages [40, 46], a "frequently asked questions" section [44], video animations [43] and videos with healthcare professionals and/or educational information and advice [36, 37, 39]. The interventions by Foster et al. [38], Paxton et al. [42] and Myall et al. [45] released their contents weekly. Foster et al. [38], Harder et al. [44], Lee et al. [40, 46] and Myall et al. [45] involved the use of a diary. Additional information for signposting was provided in most interventions: Foster et al. [38], Harder et al. [44], Kanara et al. [36, 39], Melissant et al. [41], Myall et al. [45] and Willems et al. [37].

\section{Quality assessment and inter-rater reliability}

All included studies were rated as having "good" or "strong" methodological quality. The overall qualitative and quantitative combined quality scores ranged from 75 to $100 \%$ (median score: $92 \%$, IQR: $17.5 \%$ ). Tables 6 and 7 show the quality scorings for each criterion for all qualitative and quantitative design studies, respectively, and the inter-rater levels of agreement. A substantial level of agreement between the assessors on seven of the 11 included articles was achieved. Adjusting the calculations with weighted kappa values, the raters achieved "almost perfect" agreements on seven of the 11 articles, a substantial agreement on one article and a slightly lower, but moderate agreement on two articles (Tables 6 and 7).

Two articles $[44,45]$ were assessed with the qualitative checklist and achieved scores of 75\% (implying good methodological quality,) and 80\% (implying strong methodological quality), respectively. Both articles fully satisfied six out of ten quality criteria (Table 6). However, neither of the articles presented evidence of verification procedures in order to support the credibility of their qualitative results.

Nine articles [36-43, 46] were assessed with the quantitative checklist and achieved quality scores that ranged between $75 \%$ and $100 \%$ (median score: $92 \%$, IQR: 12\%). Table 7 shows that all articles have achieved scorings indicating "strong" methodological quality (> 80\%), apart from the two articles by Lee and colleagues $[40,46]$ which were categorized as having a "good" methodological quality. All articles achieved maximum scores on four of the criteria. In all but one 
RCT [40], the nature of the study designs precluded subject blinding and that criterion was marked as non-applicable. Although participant blinding was deemed as being possible and attempted in Lee et al. [40] by not informing the participants whether they were allocated to the interventional or to the control groups, there was no evidence that this was achieved. This is so since the authors acknowledged that some of the participants might have guessed that the WSEDI intervention was the one being tested [40]. The study design allowed possible blinding of the investigators in five of the articles [36-40]; however, only Foster et al. [38] presented evidence for appropriate investigator blinding procedures. One article [46] failed to report the recruitment process and the gender of their participants.

\section{Main outcomes of interest}

The three main outcomes of interest (adherence and usage, acceptability and satisfaction) were analysed across all included 11 studies, as long as these were present in them, irrespective of the type of methodology and findings that these studies possessed: quantitative, qualitative or mixed quantitative and qualitative. The findings concerning adherence and usage were analysed in all studies, except for the qualitative only study by Myall et al. [45] as this outcome was not described in it. The outcomes for acceptability were described in one of the two studies with mixed qualitative and quantitative methodologies and findings [38], also in both qualitative studies $[44,45]$ and in one out of the seven quantitative studies [40].

\section{Adherence and usage}

Adherence to the interventions was measured and described in all articles, except for Myall et al. [45]. Predominantly, this was achieved by tracking login and usage data or self-reported measures (Table 5). Adherence levels across the included articles were generally high, but the longer the intervention period and follow-up lasted, the lower the adherence levels were. Follow-up periods varied between 1 week [41] and 12 months in Kanera et al. [36]. Adherence was mainly measured in percentages and varied between $10.1 \%$ at 6 months [39] to $100 \%$ for at 8 weeks in Harder et al. [44]. Most studies had predefined cut-off levels of adherence [36-42]. Foster et al. [38] considered participants as adherent if at least two out of five modules were accessed; Kanera et al. [36] required at least three pages accessed within each module for adherence.

\section{Acceptability}

Acceptability was measured in four studies [38, 40, 44, 45] describing three interventions. Based on the provided outcomes for acceptability across the four studies that measured it, the majority of the participants across these studies had positive feedback and opinions of the interventions they were using, finding the interventions acceptable and beneficial, which led to positive behaviour and lifestyle changes (Table 5). Foster et al. [38] measured acceptability by exploring participants' perceptions of the intervention timing, the attrition rate $(36 \%)$, identified benefits from participation, adherence levels $(71 \%)$ and preferred mode of access (50\% preferred using the RESTORE intervention along with a leaflet). Harder et al. [44] measured acceptability of their intervention by exploring its usability and attractiveness during a focus group discussion, whereas Lee et al. [40] measured the participation in the programme during the interventional period (89\%). The level of acceptability was determined through telephone interviews in Myall et al. [45], where the authors found that participants benefited from using the intervention, and this resulted in a positive lifestyle behaviour change for the majority of their participants.

\section{Satisfaction}

Satisfaction with the intervention was reported in three articles [41-43] using different outcome measures (Table 5) and was predominantly positively evaluated by intervention users. Only in Melissant et al.'s [41] satisfaction was negatively reported: net promoter score (NPS) was negative at -36 (range: -100 to +100 describing how many of the intervention users would promote it to others (if more than the antipromoters, then this is considered positive", how many would not promote it to others and how many would take a passive stance and would neither promote it). Apart from this, their other satisfaction outcomes were positive: mean score for satisfaction with the intervention was 6.9 out of 10 and with the specific BC module-7.6 out of 10. The "Learn", the "Selfcare advice" and the "Act" modules were all viewed by more than $50 \%$ of the participants. Cnossen et al. [43] measured satisfaction with the overall intervention (84\%), userfriendliness (74\%), overall satisfaction $(66 \%)$ and a net promoter score $(\mathrm{NPS}=+5)$. Paxton et al. [42] used a 5-point Likert scale to measure overall satisfaction and satisfaction levels with the intervention components. They also found that $97 \%$ of their respondents would recommend the intervention with the most popular component being the "Educational Information" and the least popular component being "Functionality". However, no significant between-group differences regarding overall satisfaction were found.

\section{Secondary outcomes of interest}

\section{Moderating factors and associations affecting adherence, acceptability or satisfaction}

Moderating factors and associations affecting intervention adherence, acceptability or satisfaction were reported, 
respectively, in two studies [36, 43]. Kanera et al. [36] found that younger participants (age $<57$ years) used the intervention significantly more which proved that younger age, unlike gender, education level and use of the physical activity (PA) module, positively affected intervention use at 6 months ( $p=$ $0.040)$ and at 12 months $(p=0.000)$. This effect of moderation was also confirmed by secondary analyses. Conversely, Cnossen et al. [43] did not conduct analysis that assesses moderations; however, they found a statistically significant positive association between satisfaction with their intervention and education level $(p=0.004)$ and also for health literacy skills positively affecting satisfaction levels $(p=0.038)$-i.e. the higher the levels of educational level and health literacy skills, the higher levels of satisfaction with the intervention.

\section{Other outcomes of interest}

\section{Barriers and facilitators to intervention usage}

Barriers and facilitators to intervention usage and adherence were explored by Lee et al. [46], Melissant et al. [41] and Myall et al. [45] through (telephone) semi-structured interviews and surveys. Barriers were identified as the intervention being too extensive [41] and having lack of time, new skills needed and negative impacts from cancer memories [45]. Common facilitators for usage were when the scoring for well-being generated by the intervention was similar (41\%) to participants' own perceptions [41], and accessible, easy-to-understand language was used within the intervention [45]. Lee et al. [46] also measured perceived ease of use and reported that their intervention was perceived as easy to use and understand, with a mean usability score of $81.3 / 100$ $(\mathrm{SD}=20)$. Paxton et al. [42] found no significant betweengroup difference for another self-reported outcome, perceived effectiveness of the intervention, which meant that the PA and the Diet groups who used the online intervention perceived it to be similarly effective (Table 5).

\section{Suggestions for improvement}

Suggestions for improvement of interventions were requesting additional demonstration videos or sections including frequently asked questions [44], more specific information, precautionary advice [46], quicker access to the intervention postoperatively, improved intervention interface and equal opportunities to access the intervention regardless of social, economic and geographical factors [45].

\section{Discussion}

The aim of this review was to evaluate the current literature and explore adherence, acceptance and satisfaction with
Internet self-management interventions for cancer rehabilitation after surgery and whether intervention features or other factors affected these outcomes. The studies reported in this review were classified as having "good" to "strong" methodological quality. Evidence was provided that participants were more inclined to be satisfied with, to accept and adhere to the interventions if the following criteria were present: the intervention was time and cost-efficient, required the acquisition of minimal or no new skills, was presented with coherent language, was offered as soon as possible after cancer treatments and contained the essential precautionary and educational information relevant to and tailored for the individual user. These findings are supported by another systematic review of web-based interventions for symptom management in cancer patients by Fridriksdottir et al. [47]. These authors reported that web-based interventions can have a positive effect on cancer symptoms management provided that the interventions are timely and include evidence-based information, tailored feedback and self-management components.

There was a wide range of adherence to interventions that varied across the studies. Analysis showed that adherence was significantly better where contents had been personally chosen by the users [42], interventions with personalized information $[40,43,45]$ and interventions with tailored information $[41,44]$. A similar wide range of adherence to healthcare web-based interventions, directly correlated to the intervention duration, was also noted by Kelders et al. [26] in their systematic review. Results showed that all interventions with adherence above $80 \%$ lasted between 6 and 21 weeks, and with average adherence levels to these interventions of $55 \%$, whereas interventions with durations ranging between 52 to 130 weeks had an average adherence level of $39 \%$.

Kelders et al. [26] also correlate web-based intervention adherence to its "intended usage", i.e. to the recommended by the intervention creators "extent" of usage for gaining maximum benefits from the treatment intervention. However, only a few studies mention intention to use the intervention in some form. Lee et al. [40] mention "intended usage" in their study and the fact that they have provided the information about the intended usage of the intervention to their study participants in the form of a manual containing recommended optimal for the user dietary or exercise parameters. Kanera et al. [36] mention the "intended action" as a feature in their action planning component, referring to a specified action to be done by the participants, in order to perform a given behaviour change. Melissant et al. [41] have predefined the feasibility of their intervention as $50 \%$ or more adoption and usage "as intended, based on login data", however, not providing a clear description of what the intended usage as per login data was. Another study in this review provided recommended cut-off rates of usage based on physical activity and dietary guidelines in the field of the intervention [42]. As per the definition provided by Kilders et al. [26], one could argue that the intended usage of 
an intervention can match the predefined cut-off usage levels by most of the authors that measured adherence in this review and predefined these. However, some of the studies did not provide an accurate description of the predefined intended cutoff usage levels or a rationale for the predefined usage levels [37], and whether or not these predefined usage levels were expected to bring more benefits to the user compared with less usage of the intervention [36, 39]. Some studies did not specify any predefined cut-off usage levels at all $[44,46]$. The last two comments imply a potential knowledge gap showing the need for intervention designers to explicitly describe the intended usage of an intervention rationalizing the benefits that the intended levels of usage would bring to the intervention user.

Education level was reported to be a moderating factor for intervention adherence with significant correlation between the two described by Cnossen et al. [43] and with nonsignificant correlation between education level and adherence reported by Kanera et al. [36]. When considering the results of the two studies, it should be noted that the sample size in the RCT by Kanera et al. [36] was nearly ten times larger than the sample by Cnossen et al. [43]. Moreover, only Kanera et al. [36] analysed their data based on the intention-to-treat (ITT) principle which generally provides a less biased estimation of treatment effectiveness [48] and thus makes the results of this study more reliable than others [48]. Also related to the reliable reporting of study samples, failing to report the recruitment process and the gender of their participants, as did the authors in Lee et al. [46], is a major flaw in this article. Poor recruitment reporting can also inflict significant risk of bias and thus reduce the quality of a study [49].

Three interventions described by Cnossen et al. [43]; Kanera et al. [36, 39]/Willems et al. [37] and by Paxton et al. [42] were based on a theoretical rationale, and no public or patient involvement in the designing of these interventions was described which suggests that these authors may have omitted the inclusion of features or components that the intervention users would have liked or preferred. For instance, based on their users' qualitative feedback, Harder et al. [44] added a "Frequently Asked Questions" option, a symptoms diary and tailored information sections, and they paraphrased some of the wording so that the intervention better reflected the users' preferences. As the authors noted, this could have improved the user testing feedback and adherence to their intervention.

In terms of satisfaction, two studies had an opposing NPS: a positive NPS by Cnossen et al. [43] by head-and-neck (HAN) cancer survivors, versus a negative NPS by Melissant et al. [41] by their BC survivors. Since satisfaction levels have been correlated with adherence levels, exploring satisfaction can provide useful insight to researchers in terms of improving patients' adherence to Internet-based interventions [28].
No studies reported any negative feedback related to acceptability of Internet interventions. A study by Short et al. [50] specifically looked into different delivery schedules of their intervention. Although this study was not included in this review due to unclear surgical status of their participants, it interestingly showed that an Internet intervention delivered monthly over 3 months was more acceptable for the participants compared with weekly delivered modules or as a oneoff interventional episode. Moreover, Ryhanen et al. [51], in their systematic review of educational Internet or interactive computer-based interventions, aiming to increase the patients' information and awareness of breast cancer and its symptoms, also synthesized some results showing that spending more time using the interactive interventions increased the information competence of the intervention users, compared with spending less interaction time. However, the authors of this review pointed out that the majority of the interventions included were delivered as a one-off session, instead of an intervention on a continuous basis. This therefore imposes questioning regarding the positive finding about spending more time with the interventions, implying that this finding was not a common observation, but rather a one-off finding from one of the studies included in that review. There is therefore a need for more research in the field of mode of delivery of the interventions in terms of duration and frequency of interaction with such web-based health-related interventions.

In terms of the outcomes describing suggestions for improvements, four out of seven interventions-the RESTORE intervention [38, 45], the bWell intervention [44], the Oncokompas intervention [41] and the WSEDI intervention by Lee and colleagues $[40,46]$ —involved people with cancer during their design and development stages, as recommended by the clinical guidelines for healthcare decision-making by Nilsen et al. [52] and other authors in the field of Internet health intervention design [18, 53, 54]. However, within this review, no correlation between the cancer patients' involvement in the intervention designing and improved outcomes for intervention use was found.

\section{Limitations}

This review has some limitations. Firstly, it included only studies published in English, which may potentially discount other valid studies that may have been published in another language. Secondly, although this review aimed to focus only on interventions for postoperative exercising and rehabilitation, some of the participants included across the studies (one-third or less from each study sample) had not undergone surgical treatment. However, the studies were deemed appropriate for inclusion as the majority of their participants had undergone surgical treatment for cancer. 


\section{Strengths and implications for research}

This review was based on thorough and systematic searches and included independent reviewers screening the selected articles and assessing the quality of the final selection. Identification of common positive intervention features and components will facilitate developers to build future Internet interventions that will improve the provision of rehabilitation services for cancer survivors, the majority of whom receive surgery after diagnosis and deal with its consequences afterwards.

\section{Conclusions and recommendations}

Based on studies with good to strong methodological quality, this review provides evidence suggesting that Internet selfmanagement interventions for postoperative cancer rehabilitation can be satisfactory, acceptable and usable, as long as:

- They contain tailored, succinct information.

- They are written in coherent and plain language.

- No or minimal new skills are required.

- They do not take excessive time to complete.

Due to the scarcity of RCTs, the findings from this review should be treated with caution. Despite no limitations on publication year being set, the short publication span of 5 years indicates the lack of accumulated empirical evidence regarding these novel interventions. This implies the need for future more rigorous, large-scaled clinical trials to be conducted in this area.

Acknowledgements The authors would like to thank Mary Rose Holman and Kelly McCoo for their expert guidance and advice for conducting the searches for this systematic review.

Funding This review was undertaken as part of a $\mathrm{PhD}$ studentship at Ulster University (MS) and funded by the Department for the Economy (DfE) Studentship.

\section{Compliance with ethical standards}

Conflict of interest Author Miss Mariya B. Sotirova declares that she has no conflict of interest.

Author Prof. Eilis M. McCaughan declares that she has no conflict of interest.

Author Dr. Lucia Ramsey declares that she has no conflict of interest.

Author Dr. Carrie Flannagan declares that she has no conflict of interest.

Author Dr. Daniel P. Kerr declares that he has no conflict of interest.

Author Dr. Sean R. O'Connor declares that he has no conflict of interest.

Author Dr. Nicole E. Blackburn declares that she has no conflict of interest.

Author Dr. Iseult M. Wilson declares that she has no conflict of interest.
Ethical approval This article does not contain any studies with human participants or animals performed by any of the authors.

Open Access This article is licensed under a Creative Commons Attribution 4.0 International License, which permits use, sharing, adaptation, distribution and reproduction in any medium or format, as long as you give appropriate credit to the original author(s) and the source, provide a link to the Creative Commons licence, and indicate if changes were made. The images or other third party material in this article are included in the article's Creative Commons licence, unless indicated otherwise in a credit line to the material. If material is not included in the article's Creative Commons licence and your intended use is not permitted by statutory regulation or exceeds the permitted use, you will need to obtain permission directly from the copyright holder. To view a copy of this licence, visit http://creativecommons.org/licenses/by/4.0/.

\section{References}

1. Cancer Research UK. Cancer survival statistics. Cancer Research UK. 2014. https://www.cancerresearchuk.org/health-professional/ cancer-statistics/survival\#heading-Zero Accessed 15 January 2020.

2. National Cancer Registration \& Analysis Service and Cancer Research UK: "Chemotherapy, radiotherapy and tumour resections in England: 2013-2014" workbook. London: NCRAS. 2017. http://www.ncin.org.uk/cancer_type_and_topic_specific work/topic specific work/main cancer treatments. Accessed $2 \overrightarrow{5}$ September 2019.

3. Silver J, Baima J, Newman R, Galantino M, Shockney L. Cancer rehabilitation may improve function in survivors and decrease the economic burden of cancer to individuals and society. Work. 2013;46(4):455-72. https://doi.org/10.3233/WOR-131755.

4. Bouknight R, Bradley C, Luo Z. Correlates of return to work for breast cancer survivors. J Clin Oncol. 2006;24(3):345-53. https:// doi.org/10.1200/JCO.2004.00.4929.

5. Short P, Vasey J, Tunceli K. Employment pathways in a large cohort of adult cancer survivors. J Cancer. 2005;103(6):1292301. https://doi.org/10.1002/cncr.20912.

6. Hewitt M, Greenfield S, Stoval M, editors. From cancer patient to cancer survivor. Washington, D.C.: National Academies Press; 2006.

7. Macmillan Cancer Support. Cancer rehabilitation pathways. In Cancer rehabilitation pathways. Macmillan Cancer Support. 2018. https://www.macmillan.org.uk/assets/macmillan-cancerrehabilitation-pathways.pdf. Accessed 22 November 2019.

8. Cascella M, Thompson NS, Muzio MR, Forte CA, Cuomo A. The underestimated role of psychological and rehabilitation approaches for management of cancer pain. A brief commentary. Recenti Prog. Med. 2016;107(8):418-21 http://www.recentiprogressi.it/allegati/ 02332_2016_08/fulltext/05_Rassegna\%20-\%20Cascella.pdf. Accessed 2 December 2019.

9. Saggini R, Bellomo RG, Carmignano SM, Saggini A. Cancer pain - the role of an integrated, comprehensive rehabilitation program in its management. Updates on Cancer Treatment. 2015;61: $116 \mathrm{https} / / \mathrm{www}$.intechopen.com/books/updates-oncancertreatment/cancer-pain-the-role-of-an-integratedcomprehensiverehabilitation-program-in-its-management. Accessed 25 September 2019. https://doi.org/10.5772/60548.

10. Chasen M, et al. Curr Oncol. 2008;15(3):117 https://www.ncbi. nlm.nih.gov/pmc/articles/PMC2442766/ Accessed 3 February 2020.

11. Department of Health, Macmillan Cancer Support, NHS Improvement. National cancer survivorship initiative vision. 
Department of Health. 2010. www.ncsi.org.uk/wp-content/ uploads/NCSI-Vision-Document.pdf. Accessed 15 January 2020.

12. Segal R, Zwaal C, Green E, Tomasone J, Loblaw A, Petrella T, et al. Exercise for people with cancer: a clinical practice guideline. Curr Oncol. 2017;24(1):40-6. https://doi.org/10.3747/co.24.3376.

13. Rock CL, Doyle C, Demark-Wahnefried W, Meyerhardt J, Courneya KS, Schwartz AL, et al. Nutrition and physical activity guidelines for cancer survivors. CA Cancer J Clin. 2012;62(4): 242-74. https://doi.org/10.3322/caac.21142.

14. Schmitz K, Courneya K, Matthews C, Demark-Wahnefried W, GALVÃO D, Pinto B, et al. American college of sports medicine roundtable on exercise guidelines for cancer survivors. Med Sci Sports Exerc. 2010;42(7):1409-26. https://doi.org/10.1249/MSS. 0b013e3181e0c112.

15. Thorsen L, Gjerset G, Loge J, Kiserud C, Skovlund E, Fløtten T, et al. Cancer patients' needs for rehabilitation services. Acta Oncol. 2011;50(2):212-22. https://doi.org/10.3109/0284186X.2010. 531050.

16. Goode A, Lawler S, Brakenridge C, Reeves M, Eakin E. Telephone, print, and web-based interventions for physical activity, diet, and weight control among cancer survivors: a systematic review. J Cancer Surviv. 2015;9(4):660-82. https://doi.org/10.1007/ s11764-015-0442-2.

17. Rogers M, Lemmen K, Kramer R, Mann J, Chopra V. Internetdelivered health interventions that work: systematic review of meta-analyses and evaluation of website availability. J Med Internet Res. 2017;19(3):e90. https://doi.org/10.2196/jmir.7111.

18. Yardley L, Spring B, Riper H, Morrison L, Crane D, Curtis K, et al. Understanding and promoting effective engagement with digital behavior change interventions. Am J Prev Med. 2016;51(5):83342. https://doi.org/10.1016/j.amepre.2016.06.015.

19. Morrison L, Moss-Morris R, Michie S, Yardley L. Optimizing engagement with Internet-based health behaviour change interventions: comparison of self-assessment with and without tailored feedback using a mixed methods approach. Br J Health Psychol. 2014;19(4):839-55. https://doi.org/10.1111/bjhp.12083.

20. Krebs P, Prochaska J, Rossi J. A meta-analysis of computer-tailored interventions for health behavior change. Prev Med. 2010;51(3-4): 214-21. https://doi.org/10.1016/j.ypmed.2010.06.004.

21. Hennemann S, Beutel M, Zwerenz R. Drivers and barriers to acceptance of web-based aftercare of patients in inpatient routine care: a cross-sectional survey. J Med Internet Res. 2016;18(12):e337. https://doi.org/10.2196/jmir.6003.

22. van der Vaart R, Atema V, Evers A. Guided online selfmanagement interventions in primary care: a survey on use, facilitators, and barriers. BMC Fam Pract. 2016;17(1). https://doi.org/ 10.1186/s12875-016-0424-0.

23. Higgins JPT, Thomas J, Chandler J, Cumpston M, Li T, Page MJ, Welch VA, editors. Cochrane handbook for systematic reviews of interventions version 6.0 (2019). Cochrane Database Syst Rev 2019; www.training.cochrane.org/handbook. Accessed 25 January 2020.

24. Moher D. 14. Moher D, Liberati A, Tetzlaff J, Altman D. Preferred reporting items for systematic reviews and meta-analyses: the PRISMA statement. Ann Intern Med. 2009;151(4):264-9. https:// doi.org/10.7326/0003-4819-151-4-200908180-00135.

25. Bennett GG, Glasgow RE. The delivery of public health interventions via the Internet: actualizing their potential. Annu Rev Public Health. 2009;30:273-92. https://doi.org/10.1146/annurev. publhealth.031308.100235.

26. Kelders S, Kok R, Ossebaard H, Van Gemert-Pijnen J. Persuasive system design does matter: a systematic review of adherence to web-based interventions. J Med Internet Res. 2012;14(6):e152. https://doi.org/10.2196/jmir.2104.

27. Sekhon M, Cartwright M, Francis J. Acceptability of healthcare interventions: an overview of reviews and development of a theoretical framework. BMC Health Serv Res. 2017;17(1):88. https://doi.org/10.1186/s12913-017-2031-8.

28. Boß L, Lehr D, Reis D, Vis C, Riper H, Berking M, et al. Reliability and validity of assessing user satisfaction with web-based health interventions. J Med Internet Res. 2016;18(8):e234. https://doi. org/10.2196/jmir.5952.

29. Jonkman N, Schuurmans M, Jaarsma T, Shortridge-Baggett L, Hoes A, Trappenburg J. Self-management interventions: proposal and validation of a new operational definition. J Clin Epidemiol. 2016;80:34-42. https://doi.org/10.1016/j.jclinepi.2016.08.001.

30. Kmet L M, Lee R C, Cook L S. Standard quality assessment criteria for evaluating primary research papers from a variety of fields. Edmonton: Alberta Heritage Foundation for Medical Research (AHFMR). AHFMR - HTA Initiative \#13. 2004. https://doi.org/ 10.7939/R37M04F16.

31. Lee L, Packer T, Tang S, Girdler S. Self-management education programs for age-related macular degeneration: a systematic review. Australas J Ageing. 2008;27(4):170-6. https://doi.org/10. 1111/j.1741-6612.2008.00298.x.

32. Maharaj S, Harding R. The needs, models of care, interventions and outcomes of palliative care in the Caribbean: a systematic review of the evidence. BMC Palliat Care. 2016;15(1):9. https://doi.org/10. 1186/s12904-016-0079-6.

33. Cohen J. A coefficient of agreement for nominal scales. Educ Psychol Meas. 1960;20(1):37-46. https://doi.org/10.1177/ 001316446002000104.

34. Cohen J. Weighted kappa: nominal scale agreement provision for scaled disagreement or partial credit. Psychol Bull. 1968;70(4): 213-20. https://doi.org/10.1037/h0026256.

35. Popay J, Roberts H, Sowden A, Petticrew M, Arai L, Rodgers M, et al. Guidance on the conduct of narrative synthesis in systematic reviews. A product from the ESRC methods programme version, vol. 1. Bailrigg: Lancaster University; 2006. p. 1-92. https://doi. org/10.13140/2.1.1018.4643.

36. Kanera I, Willems R, Bolman C, Mesters I, Verboon P, Lechner L. Long-term effects of a web-based cancer aftercare intervention on moderate physical activity and vegetable consumption among early cancer survivors: a randomized controlled trial. Int J Behav Nutr Phys Act. 2017;14(1):19. https://doi.org/10.1186/s12966-0170474-2.

37. Willems R, Bolman C, Mesters I, Kanera I, Beaulen A, Lechner L. Short-term effectiveness of a web-based tailored intervention for cancer survivors on quality of life, anxiety, depression, and fatigue: randomized controlled trial. Psychooncology. 2017;26(2):222-30. https://doi.org/10.1002/pon.4113.

38. Foster C, Grimmett C, May C, Ewings S, Myall M, Hulme C, et al. A web-based intervention (RESTORE) to support self-management of cancer-related fatigue following primary cancer treatment: a multi-centre proof of concept randomised controlled trial. Support Care Cancer. 2016;24(6):2445-53. https://doi.org/10.1007/s00520015-3044-7.

39. Kanera I, Bolman C, Willems R, Mesters I, Lechner L. Lifestylerelated effects of the web-based Kanker Nazorg Wijzer (Cancer aftercare guide) intervention for cancer survivors: a randomized controlled trial. J Cancer Surviv. 2016;10(5):883-97. https://doi. org/10.1007/s11764-016-0535-6.

40. Lee M, Yun Y, Park H, Lee E, Jung K, Noh D. A web-based selfmanagement exercise and diet intervention for breast cancer survivors: pilot randomized controlled trial. Int J Nurs Stud. 2014;51(12):1557-67. https://doi.org/10.1016/j.ijnurstu.2014.04. 012.

41. Melissant H, Verdonck-de Leeuw I, Lissenberg-Witte B, Konings I, Cuijpers P, Van Uden-Kraan C. 'Oncokompas', a web-based selfmanagement application to support patient activation and optimal supportive care: a feasibility study among breast cancer survivors. 
Acta Oncol. 2018;57(7):924-34. https://doi.org/10.1080/ 0284186X.2018.1438654.

42. Paxton R, Hajek R, Newcomb P, Dobhal M, Borra S, Taylor W, et al. A lifestyle intervention via email in minority breast cancer survivors: randomized parallel-group feasibility study. JMIR Cancer. 2017;3(2):e13. https://doi.org/10.2196/cancer.7495.

43. Cnossen I, van Uden-Kraan C, Eerenstein S, Jansen F, Witte B, Lacko M, et al. An online self-care education program to support patients after total laryngectomy: feasibility and satisfaction. Support Care Cancer. 2016;24(3):1261-8. https://doi.org/10.1007/ s00520-015-2896-1.

44. Harder H, Holroyd P, Burkinshaw L, Watten P, Zammit C, Harris $\mathrm{P}$, et al. A user-centred approach to developing bWell, a mobile app for arm and shoulder exercises after breast cancer treatment. J Cancer Surviv. 2017;11(6):732-42. https://doi.org/10.1007/ s11764-017-0630-3.

45. Myall M, May C, Grimmett C, May C, Calman L, Richardson A, et al. RESTORE: an exploratory trial of a web-based intervention to enhance self-management of cancer-related fatigue: findings from a qualitative process evaluation. BMC Med Inform Decis Mak. 2015;15(1):94. https://doi.org/10.1186/s12911-015-0214-y.

46. Lee M, Park H, Yun Y, Chang Y. Development and formative evaluation of a web-based self-management exercise and diet intervention program with tailored motivation and action planning for cancer survivors. JMIR Res Protoc. 2013;2(1):e11. https://doi.org/ 10.2196/resprot.2331.

47. Fridriksdottir N, Gunnarsdottir S, Zoëga S, Ingadottir B, Hafsteinsdottir E. Effects of web-based interventions on cancer patients' symptoms: review of randomized trials. Support Care Cancer. 2018;26(2):337-51. https://doi.org/10.1007/s00520-0173882-6.

48. Montori VM, Guyatt GH. Intention-to-treat principle. Can Med Assoc J. 2001;165(10):1339-41 https://www.cmaj.ca/content/165/ 10/1339.long. Accessed 3 March 2020.
49. Page S, Persch A. Recruitment, retention, and blinding in clinical trials. Am J Occup Ther. 2013;67(2):154-61. https://doi.org/10. 5014/ajot.2013.006197.

50. Short C, Rebar A, James E, Duncan M, Courneya K, Plotnikoff R, et al. How do different delivery schedules of tailored web-based physical activity advice for breast cancer survivors influence intervention use and efficacy? J Cancer Surviv. 2017;11(1):80-91. https://doi.org/10.1007/s11764-016-0565-0.

51. Ryhänen A, Siekkinen M, Rankinen S, Korvenranta H, Leino-Kilpi $\mathrm{H}$. The effects of Internet or interactive computer-based patient education in the field of breast cancer: a systematic literature review. Patient Educ Couns. 2010;79(1):5-13. https://doi.org/10. 1016/j.pec.2009.08.005.

52. Nilsen ES, Myrhaug HT, Johansen M, Oliver S, Oxman AD. Methods of consumer involvement in developing healthcare policy and research, clinical practice guidelines and patient information material. Cochrane Database Syst Rev. 2006;3:CD004563. https://doi.org/10.1002/14651858.CD004563.pub2.

53. Yardley L, Morrison L, Bradbury K, Muller I. The person-based approach to intervention development: application to digital healthrelated behavior change interventions. J Med Internet Res. 2015;17(1):e30. https://doi.org/10.2196/jmir.4055.

54. Duncan E, O'Cathain A, Rousseau N, Croot L, Sworn K, Turner K, et al. Guidance for reporting intervention development studies in health research (GUIDED): an evidence-based consensus study. BMJ Open. 2020;10(4):e033516. https://doi.org/10.1136/ bmjopen-2019-033516.

Publisher's note Springer Nature remains neutral with regard to jurisdictional claims in published maps and institutional affiliations. 